\title{
Role of TRPM8 in Switching Between Fever and Hypothermia in Adult Mice During Endotoxin- Induced Inflammation
}

\section{Chinatsu Shiraki}

Kyoto Institute of Technology

\section{Ririka Horikawa}

Kyoto Institute of Technology

\section{Momoka Fujimoto}

Kyoto Institute of Technology

Kaho Okamoto

Kyoto Institute of Technology

\section{Erkin Kurganov}

Kyoto Institute of Technology

Seiji Miyata ( $\nabla$ smiyata@kit.ac.jp )

Kyoto Institute of Technology

\section{Research Article}

Keywords: TRPM8, KO, LPS

Posted Date: December 10th, 2020

DOl: https://doi.org/10.21203/rs.3.rs-120058/v1

License: (c) (i) This work is licensed under a Creative Commons Attribution 4.0 International License. Read Full License

Version of Record: A version of this preprint was published at Brain, Behavior, \& Immunity - Health on October 1st, 2021. See the published version at https://doi.org/10.1016/j.bbih.2021.100291. 


\title{
Role of TRPM8 in switching between fever and
}

\section{hypothermia in adult mice during endotoxin-}

\author{
induced inflammation
}

Chinatsu Shiraki, Ririka Horikawa, Momoka Fujimoto, Kaho Okamoto, Erkin Kurganov, Seiji Miyata

Department of Applied Biology, Kyoto Institute of Technology, Matsugasaki, Sakyo-ku, Kyoto 606-8585, Japan.

KEYWORDS: TLR4, TLR2, LPS, zymosan, IL-1 $\beta$, inflammation, brain

Running title: TRPM8 in fever and hypothermia

Correspondence:

Seiji Miyata (smiyata@kit.ac.jp)

Department of Applied Biology, Kyoto Institute of Technology, Kyoto 606-8585, Japan. 
Scientific Reports

\begin{abstract}
Transient receptor potential melastatin 8 (TRPM8) functions in the sensing of noxious and innocuous colds; however, its significance in pathogen-induced thermoregulation and inflammation remains unclear. In the present study, we investigated the role of TRPM8 in the regulation of endotoxin-induced body temperature control and inflammation. The peripheral administration of low-dose LPS or zymosan generated fever in wild-type (WT) mice and hypothermia in TRPM8 knockout (KO) animals. TRPM8 KO mice exhibited severe hypothermia and sickness responses following the peripheral administration of high-dose LPS. An intracerebroventricular (i.c.v.) injection of LPS and interleukin-1ß (Il-1ß) elicited hypothermia in TRPM8 KO mice, in contrast to fever in WT animals, whereas that of prostaglandin $\mathrm{E}_{2}$ induced normal fever. Fos immunohistochemistry showed the stronger activation of hypothalamic thermoregulation-associated nuclei following the peripheral administration of low-dose LPS. Therefore, TRPM8 is necessary for switching between fever and hypothermia during endotoxin-induced inflammation.
\end{abstract}




\section{Introduction}

The recognition of pathogen infections is one of the most important mechanisms of innate immunity for eliminating pathogens and the first line of host defense against infection ${ }^{1}$. Several families of pattern recognition receptors are responsible for detecting the pathogen-associated molecular patterns (PAMPs) of many pathogens ${ }^{2}$. Toll-like receptors (TLRs) are the most important and widely studied pattern recognition receptors ${ }^{2,3}$. The infection-induced activation of immune cells via TLRs leads to a broad spectrum of sickness symptoms, such as body temperature changes, nausea, decreased appetite, malaise, and fatigue, which are adaptive responses to promote animal survival ${ }^{4}$.

Fever is generated by integrated physiological and neuronal responses that confer a survival benefit against infection. The inhibition of fever with antipyretic drugs was previously reported to increase mortality in humans infected with influenza virus ${ }^{5}$. Fever enhances immunoprotective mechanisms in both the innate and adaptive immune systems, such as the acceleration of cytokine production and the cellular cytotoxic activity of dendritic cells, natural killer cells, macrophages as well as signaling by and the differentiation of T cells ${ }^{6}$. Fever also results in an increased metabolic rate, with only a $1^{\circ} \mathrm{C}$ increase in body temperature elevating the metabolic rate by approximately $10 \%{ }^{7}$.

Hypothermia occurs in the most severe cases of systemic inflammatory syndromes instead of fever and is regarded as an adaptive host strategy to attenuate the harmful effects caused by the overshoot of inflammatory responses ${ }^{8}$. Hypothermia suppresses endotoxin increases, abdominal organ dysfunction, hypotension, and mortality in animals injected with Escherichia coli ${ }^{9}$. More specifically, the intraperitoneal administration of the TLR4 agonist, lipopolysaccharide (LPS), was shown to induce fever or hypothermia in a dose-dependent manner: a low dose of 50 100 $\mu \mathrm{g} / \mathrm{kg}$ induced fever, whereas a high dose of more than $2.5 \mathrm{mg} / \mathrm{kg}$ caused hypothermia ${ }^{10,11}$. The intraperitoneal administration of a low dose of the TLR2 agonist zymosan of $1 \sim 10 \mathrm{mg} / \mathrm{kg}$ induced fever ${ }^{12}$, whereas a high dose of more than $50 \mathrm{mg} / \mathrm{kg}$ caused 
hypothermia ${ }^{13}$. Therefore, the two thermoregulatory responses are complementary strategies of survival in infection-induced inflammation; however, limited information is currently available on the switching mechanism between fever and hypothermia.

Prostaglandin $\mathrm{E}_{2}\left(\mathrm{PGE}_{2}\right)$, a lipid mediator, plays a key role in eliciting fever or hypothermia by acting on prostaglandin EP receptors in the preoptic area (POA) of the hypothalamus ${ }^{11}$. Recent studies reported that the medial and lateral POA is an important thermoregulatory center in the brain ${ }^{14-16}$. The specialized population of these POA neurons elicits a long-lasting hypothermic and low metabolic state by acting on the dorsomedial hypothalamic nucleus $(\mathrm{DMH})^{14-16}$. The organum vasculosum of the lamina terminalis (OVLT) is one of the circumventricular organs (CVOs), which are characterized by fenestrate capillaries or the lack of the blood-brain barrier $(\mathrm{BBB})^{17}$. The OVLT has been reported to express receptors for PAMPs and cytokines ${ }^{18,19}$ and is located adjacent to the medial and lateral POA. Moreover, TLR2 and TLR4 are expressed at microglia/macrophages and astrocytes/tanycytes, respectively, in the OVLT ${ }^{20-22}$. The selective deletion of cyclooxygenase- 2 in brain endothelial cells has been shown to attenuate the fever response ${ }^{23}$. Interleukin-1 $\beta$ (IL-1 $\beta$ ) signaling in blood vessels, particularly fenestrated capillaries in the CVOs, acts as a critical signaling relay between the immune and nervous systems to cause sickness responses ${ }^{24}$.

In the present study, we aimed to elucidate whether transient receptor potential melastatin 8 (TRPM8) is involved in endotoxin-induced body temperature regulation and inflammation. TRPM8, a cold receptor for menthol, is activated by innocuous cooling to less than approximately $26^{\circ} \mathrm{C}^{25}$. TRPM8 is necessary for sensing skin cooling and, hence, TRPM8 knockout $(\mathrm{KO})$ mice are deficient for noxious and innocuous cold-evoked behaviors ${ }^{26,27}$. TRPM8 may respond to alterations in temperature decreases regardless of whether the temperature is above the activation threshold ${ }^{28,29}$. In contrast to peripheral functions, the significance of central TRPM8 in endotoxin-induced body temperature regulation and inflammation remains completely unknown; however, a recent study showed that TRPM8- 
expressing neurons were present in the POA and lateral septal nucleus (LS) of the mouse brain ${ }^{30}$. In the present study, we found that hypothermia was induced in TRPM8 KO mice, in contrast to fever in wild-type (WT) animals, by the peripheral administration of low-dose LPS and zymosan. A similar hypothermic response was observed in TRPM8 KO mice following the intracerebroventricular (i.c.v.) injection of LPS and IL-1ß despite normal fever generation with the i.c.v. injection of $\mathrm{PGE}_{2}$. Moreover, the peripheral administration of high-dose LPS induced prolonged severe hypothermia in TRPM8 KO mice. The number of Fos-expressing neurons in hypothalamic thermoregulation-associated regions was significantly higher in TRPM8 KO mice than in WT animals after the peripheral administration of low-dose LPS. These results indicate that TRPM8 plays a crucial function in switching between fever and hypothermia during endotoxin-induced inflammation.

\section{Results}

Peripheral administration of low-dose LPS induced hypothermia in TRPM8 KO mice. LPS, the most potent TLR4 agonist, is used as in vitro and in vivo experimental neuroinflammation models of bacterial infection. The intraperitoneal administration of a low dose of LPS of 50 100 $\mu \mathrm{g} / \mathrm{kg}$ has been shown to generate fever in mice, whereas a high dose of more than $2.5 \mathrm{mg} / \mathrm{kg}$ induces hypothermia ${ }^{10}$. To elucidate whether TRPM8 KO mice exhibit LPS-induced fever, the body temperature of WT and TRPM8 KO mice was measured after the intraperitoneal administration of low-dose $(50 \mu \mathrm{g} / \mathrm{kg})$ LPS. A two-way repeated measures ANOVA showed a significant effect of group $\left(\mathrm{F}_{3,243}=20.84, p<0.001\right)$ and time $\left(\mathrm{F}_{7,1944}=4.56\right.$, $p<0.001)$, but not their interaction $\left(\mathrm{F}_{21,1940}=0.90, p>0.05\right)$ on changes in core body temperature (Fig. 1a). In comparisons with mice administered saline, the body temperature of WT mice significantly increased and peaked $\left(1.03 \pm 0.35^{\circ} \mathrm{C}\right) 40 \mathrm{~min}$ after the administration of LPS, whereas that of TRPM8 KO mice markedly decreased with a nadir $\left(-2.12 \pm 0.53{ }^{\circ} \mathrm{C}\right)$ at 
$120 \mathrm{~min}$. Mice in all experiments exhibited an initial stress-induced fever as a result of handling during the administration procedure, regardless of whether the endotoxin, cytokine, or saline was administered. The temperature index was significantly higher in WT mice $(5.89 \pm 1.62$ $\left.\Delta^{\circ} \mathrm{C} \times \mathrm{hr}\right)$ after the administration of LPS than in those administered saline $(-1.18 \pm 1.51)$, whereas it was significantly lower in TRPM8 KO animals $(-6.33 \pm 3.26)$ than in those administered saline $(1.15 \pm 1.74)$ (Fig. 1b). The one-way ANOVA showed no significant changes in the cumulative locomotor activity of WT and TRPM8 KO mice following the administration of LPS (Fig. 1c and Fig. S1). Therefore, TRPM8 KO mice developed hypothermia, in contrast to fever in WT mice, in response to the peripheral administration of low-dose LPS.

\section{TRPM8 KO mice developed prolonged severe hypothermia after the peripheral} administration of high-dose LPS. To elucidate whether TRPM8 is involved in the regulation of LPS-induced hypothermia, the body temperature of WT and TRPM8 KO mice was examined after the intraperitoneal administration of high-dose $(5 \mathrm{mg} / \mathrm{kg})$ LPS. A two-way repeated measures ANOVA revealed a significant effect of group $\left(\mathrm{F}_{3,600}=488.27, p<0.001\right)$, time $\left(\mathrm{F}_{23,13800}=9.33, p<0.001\right)$, and their interaction $\left(\mathrm{F}_{69,13800}=5.59, p<0.001\right)$ on changes in core body temperature (Fig. 2a). Body temperature was significantly lower in WT mice with a nadir $\left(-3.47 \pm 0.79^{\circ} \mathrm{C}\right)$ at 365 min after the LPS administration than in those administered saline. Body temperature was also significantly lower in TRPM8 KO mice with a nadir $(-7.04 \pm$ $0.44{ }^{\circ} \mathrm{C}$ ) at 565 min after the LPS administration than in those administered saline; however, LPS-induced reductions in body temperature were more prominent in TRPM8 KO mice than in WT animals. Following the administration of LPS, the temperature index was markedly lower in WT $\left(-63.24 \pm 9.43 \Delta^{\circ} \mathrm{C} \times \mathrm{hr}\right)$ and TRPM8 $\mathrm{KO}(-105.37 \pm 7.01)$ mice than in their controls (WT, 8.17 \pm 2.75 ; TRPM8 KO, $1.07 \pm 5.96$ ) (Fig. 2b). However, the temperature index was markedly lower in LPS-treated TRPM8 KO mice than in WT mice. Locomotor activity 
Scientific Reports

during daytime and nighttime was significantly lower in LPS-treated TRPM8 KO mice than in those administered saline (Fig. 2c,d and Fig. S2). Furthermore, WT mice had slightly lower locomotor activity. These results indicate that TRPM8 KO mice developed severe hypothermia and exhibited reduced locomotor activity in response to the peripheral administration of highdose LPS.

\section{The central injection of LPS induced hypothermia in TRPM8 KO mice in the early phase.}

To elucidate whether central TRPV8 is involved in endotoxin-induced body temperature changes, the body temperature of WT and TRPM8 KO mice was measured after an i.c.v. injection of 3.6 $\mu \mathrm{g} / \mathrm{kg}$ LPS (Fig. 3). A two-way repeated measures ANOVA showed a significant effect of group $\left(\mathrm{F}_{3,168}=112.04, p<0.001\right)$, time $\left(\mathrm{F}_{7,1176}=4.69, p<0.001\right)$, and their interaction $\left(\mathrm{F}_{21,1176}=7.89, p<0.001\right)$ on alterations in core body temperature (Fig. 3a). The body temperature of WT mice was significantly higher at $30-480$ min with a peak $\left(2.19 \pm 0.28{ }^{\circ} \mathrm{C}\right)$ 255 min after the i.c.v. injection of LPS than in those administered saline. In contrast to WT mice, the body temperature of TRPM8 KO mice was markedly lower at 95-175 min with a nadir $\left(-1.99 \pm 0.59{ }^{\circ} \mathrm{C}\right)$ at $150 \mathrm{~min}$ than in those administered saline. Thereafter, it gradually returned to control levels and then was significantly higher in the later phase than that in mice administered saline. The temperature index was significantly higher in WT $(4.94 \pm 0.41$ $\left.\Delta^{\circ} \mathrm{C} \times \mathrm{hr}\right) 0 \sim 3.5 \mathrm{hr}$ after the central LPS injection than in those administered saline $(-0.45 \pm 0.51)$, whereas it was lower in TRPM8 KO mice $(-1.99 \pm 0.81)$ than in those administered saline $(0.44$ \pm 0.53 ) (Fig. 3b). The temperature index was significantly higher in WT $(7.59 \pm 0.82)$ and TRPM8 KO $(4.56 \pm 0.99)$ mice $3.5 \sim 8.0 \mathrm{hr}$ after the i.c.v. injection of LPS than in those administered saline (WT, $-1.52 \pm 0.69 ; \mathrm{KO},-0.94 \pm 0.70$ ). The one-way ANOVA showed no significant differences in locomotor activity in WT and TRPM8 KO mice following the i.c.v. injection (Fig. 3c and Fig. S3). These results indicate that the i.c.v. injection of LPS caused hypothermia in TRPM8 KO mice in the early phase, in contrast to fever in WT animals. 


\section{The peripheral administration of the TLR2 agonist zymosan only induced hypothermia} in TRPM8 KO mice. To elucidate whether TRPV8 is involved in TLR2-induced body temperature regulation, the body temperature of WT and TRPM8 KO mice was examined after the intraperitoneal administration of $10 \mathrm{mg} / \mathrm{kg}$ zymosan (Fig. 4). A two-way repeated measures ANOVA showed the significant effect of group $\left(\mathrm{F}_{3,57}=18.46, p<0.001\right)$, time $\left(\mathrm{F}_{2,114}=2.45, p\right.$ $>0.05)$, and their interaction $\left(\mathrm{F}_{6,114}=4.53, p<0.001\right)$ on changes in core body temperature after the intraperitoneal administration of zymosan (Fig. 4a). In comparisons with mice administered saline, WT and TRPM8 KO mice treated with zymosan initially showed transient hypothermia with a nadir at $40\left(\mathrm{WT} ;-2.03 \pm 0.26{ }^{\circ} \mathrm{C}\right)$ and $45 \min \left(\mathrm{KO} ;-3.63 \pm 0.45{ }^{\circ} \mathrm{C}\right)$. However, zymosan-induced reductions in body temperature were markedly smaller in TRPM8 KO mice than in WT mice. The body temperature of WT mice then increased to generate fever with a peak $\left(1.10 \pm 0.34^{\circ} \mathrm{C}\right)$ at $140 \mathrm{~min}$, whereas TRPM8 $\mathrm{KO}$ animals did not exhibit significant fever. The temperature index was significantly lower in TRPM8 KO mice $\left(-3.26 \pm 0.86 \Delta^{\circ} \mathrm{C} \times \mathrm{hr}\right)$ $0 \sim 1.5 \mathrm{hr}$ after the administration of zymosan than in those administered saline $(0.25 \pm 0.20)$, whereas zymosan did not change the temperature index (control, $-0.88 \pm 0.32$; zymosan, 0.01 \pm 0.21 ) in WT mice (Fig. 4b). The temperature index was significantly lower in TRPM8 KO mice $(-0.59 \pm 0.73) 1.5 \sim 3.0 \mathrm{hr}$ after the administration of zymosan than in those administered saline (-0.32 \pm 0.26$)$, but was significantly higher in WT animals (saline, $-0.53 \pm 0.24$; zymosan, $1.03 \pm 0.51)$. The one-way ANOVA showed no significant changes in the cumulative locomotor activity of WT and TRPM8 KO mice administered zymosan (Fig. 4c and Fig. S4). Therefore, TRPM8 KO mice only exhibited hypothermia in the early phase, in contrast to mild hypothermia in the early phase and fever in the later phase in WT animals, in response to the peripheral administration of zymosan.

The central injection of IL-1ß may cause hypothermia in the early phase and fever in the 
late phase in TRPM8 KO mice. To elucidate whether central TRPV8 is involved in IL-1 $\beta$ induced fever, the body temperature of WT and TRPM8 KO mice was measured after an i.c.v. injection of $400 \mathrm{ng} / \mathrm{kg}$ IL-1 $\beta$ (Fig. 5). A two-way repeated measures ANOVA showed a significant effect of group $\left(\mathrm{F}_{3,152}=89.65, p<0.001\right)$, time $\left(\mathrm{F}_{7,456}=2.54, p<0.05\right)$, and their interaction $\left(\mathrm{F}_{21,456}=5.88, p<0.001\right)$ on alterations in core body temperature (Fig. 5a). Body temperature was significantly higher in WT mice at 80-205 and 440-465 min with a peak (1.71 $\left.\pm 0.13{ }^{\circ} \mathrm{C}\right) 200 \mathrm{~min}$ after the i.c.v. IL-1 $\beta$ injection than in those administered saline. In contrast to WT mice, TRPM8 KO mice did not show any significant fever within $3 \mathrm{hr}$, but appeared to develop hypothermia. In comparisons with mice administered saline, the body temperature of TRPM8 KO mice gradually increased to generate significant fever at 240-480 min with a peak $\left(1.63 \pm 0.27^{\circ} \mathrm{C}\right)$ at $370 \mathrm{~min}$. The temperature index was significantly higher in WT mice $(3.37$ $\pm 0.40 \Delta^{\circ} \mathrm{C} \times \mathrm{hr}$ ) $0 \sim 3.0 \mathrm{hr}$ after the i.c.v administration of IL-1 $\beta$ than in those administered saline $(-0.02 \pm 0.47)$, whereas no significant differences were observed in the temperature index of TRPM8 KO mice between those administered IL-1 $\beta(0.18 \pm 0.72)$ and saline $(0.69 \pm 0.49)$ (Fig.

5b). The temperature index was significantly higher in WT (5.84 \pm 0.50$)$ and TRPM8 KO (5.48 \pm 1.41 ) mice $3.0 \sim 8.0 \mathrm{hr}$ after the i.c.v. administration of IL-1 $\beta$ than in those administered saline (WT, $-1.66 \pm 0.73 ; \mathrm{KO},-0.94 \pm 0.77$ ). The one-way ANOVA revealed no significant differences in locomotor activity in WT and TRPM8 KO mice following the i.c.v. IL-1 $\beta$ injection (Fig. 5c and Fig. S5). These results indicate that TRPM8 KO mice were more likely to develop hypothermia in the early phase and delayed fever generation in the later phase in response to the i.c.v. IL-1 $\beta$ injection.

\section{The colocalization of TRPM8 and PGE$_{2}$ receptor 3 (EP3R) in the POA and PGE 2 -induced} fever. Double labeling immunohistochemistry for TRPM8 and EP3R was performed to clarify whether TRPV8 is present in the EP3R-expressing neurons of the POA (Fig. 6). TRPM8 expression was prominent in the POA and LS of the hypothalamus (Fig. 6a,c). A 3D analysis 
revealed the colocalization of TRPM8 and EP3R in a POA neuron (Fig. 6b). TRPM8 was exclusively expressed in $\mathrm{EP}^{+} \mathrm{R}^{+}$neurons in the POA, whereas it was very weakly expressed in the LS due to the low density of $\mathrm{EP} 3 \mathrm{R}^{+}$neurons. The quantitative analysis revealed that the percentages of EP3R ${ }^{+}$neurons in the POA and LS expressing TRPM8 were $97.8 \pm 2.2$ and 2.6 \pm 2.6 , respectively.

To elucidate whether TRPV8 KO mice exhibit different sensitivities to $\mathrm{PGE}_{2}$, the body temperature of WT and TRPM8 KO mice was measured after an i.c.v. injection of $\mathrm{PGE}_{2}$. A twoway repeated measures ANOVA showed a significant effect of group $\left(\mathrm{F}_{5,72}=21.42, p<0.001\right)$, time $\left(\mathrm{F}_{2,144}=51.57, p<0.001\right)$, and their interaction $\left(\mathrm{F}_{10,144}=5.35, p<0.001\right)$ on changes in core body temperature (Fig. 6d). The i.c.v. injection of $160 \mathrm{nmol} / \mathrm{kg} \mathrm{PGE}_{2}$ induced rapid and robust fever in TRPM8 KO mice that was indistinguishable from that in WT mice. On the other hand, the i.c.v. injection of $16 \mathrm{nmol} / \mathrm{kg} \mathrm{PGE}_{2}$ induced significant fever in TRPM8 KO mice only. The injection of $160 \mathrm{nmol} / \mathrm{kg} \mathrm{PGE} 2$ resulted in a significantly higher temperature index in WT $\left(2.38 \pm 0.40 \Delta^{\circ} \mathrm{C} \times \mathrm{hr}\right)$ and TRPM8 KO $(1.52 \pm 0.45)$ mice than in those administered saline (WT, $0.26 \pm 0.21$; TRPM8 KO, $0.21 \pm 0.13$ ) (Fig. 6e). In comparisons with saline-treated mice, the temperature index was significantly higher in TRPM8 KO mice administered $16 \mathrm{nmol} / \mathrm{kg}$ $\mathrm{PGE}_{2}\left(0.62 \pm 0.30 \Delta^{\circ} \mathrm{C} \times \mathrm{hr}\right)$, but not in WT $(1.67 \pm 0.20)$. The temperature index was not significantly different between WT and TRPM8 KO mice following the injection of 160 nmol/kg PGE2. Furthermore, no significant differences were observed in locomotor activity between WT and TRPM8 KO mice following the PGE 2 injection (Fig. 6f and Fig. S6). These results indicate that $\mathrm{PGE}_{2}$-dependent fever generation in the brain did not significantly differ between WT and TRPM8 KO.

Augmentation of Fos expression in the hypothalamus in TRPM8 KO mice after the peripheral administration of low-dose LPS. As shown in Fig. 1, the intraperitoneal administration of low-dose LPS induced opposite thermal responses between WT and TRPM8 
KO mice: fever in WT mice and hypothermia in TRPM8 KO animals. Fos immunohistochemistry was performed to clarify whether severe brain inflammation occurs in TRPM8 KO mice (Fig. 7, 8). Immunohistochemistry revealed that many Fos ${ }^{+}$nuclei were present in the ventral part of the LS (LSV), bed nucleus of the stria terminalis (BST), lateral preoptic area (LPO), median preoptic area (MnPO), and medial preoptic area (MPA) in LPStreated WT mice (Fig. 7a,a'c,c', Fig. S7, 8). Similarly, Fos ${ }^{+}$nuclei were frequently observed in the dorsal part (LSD) and intermediate part (LSI) of the LS, LSV, BST, LPO, MnPO, and MPA of LPS-treated TRPM8 KO mice (Fig. 7b,b'd,d', Fig. S7, 8). The quantitative analysis showed that the number of $\mathrm{Fos}^{+}$nuclei was significantly increased in the LSV, BST, LPO, MnPO, and MPA of WT mice by the administration of LPS (Fig. 7e). In TRPM8 KO mice, the number of $\mathrm{Fos}^{+}$nuclei was increased by the LPS treatment in all hypothalamic regions examined. More importantly, the number of $\mathrm{Fos}^{+}$nuclei was significantly higher in the LSD, LSI, BST, and MPA of TRPM8 KO mice than in those of WT mice.

The number of Fos ${ }^{+}$nuclei in the paraventricular nucleus (PVN) and DMH was higher in LPS-treated WT mice (Fig. 8a,a',c,c') than in saline-treated mice (Fig. S9). Fos ${ }^{+}$nuclei were more frequently observed in the PVN and DMH of LPS-treated TRPM8 KO mice than in WT mice. The number of $\mathrm{Fos}^{+}$nuclei was significantly increased in the PVN and DMH of WT and TRPM8 KO animals by the administration of LPS, but was significantly higher in LPS-treated TRPM8 KO mice than in WT mice (Fig. 8c). These results indicate that Fos expression in the hypothalamus was stronger in TRPM8 KO mice than in WT animals following the peripheral administration of low-dose LPS.

\section{Discussion}

TRPM8 functions as a neuronal sensor of cold temperatures and is activated by moderate cooling and cooling agents, such as menthol and icilin ${ }^{25}$. TRPM8-deficient mice show no preference for warm temperatures over cold temperatures and have impaired cold avoidance 
behavior $^{26,31}$. Besides its role in cold sensation, TRPM8 is also involved in the suppression of inflammatory responses in colitis ${ }^{32}$ and experimental autoimmune encephalomyelitis ${ }^{33}$ and the augmentation of airway inflammatory diseases ${ }^{34}$. However, limited information is currently available on the functional significance of TRPM8 in endotoxin-induced body temperature alterations and brain inflammation. In the present study, we found that the peripheral administration of low-dose LPS induced hypothermia in TRPM8 KO mice, in contrast to fever in WT animals. Moreover, hypothermia was more severe in TRPM8 KO mice than in WT mice after the peripheral administration of high-dose LPS. Similar to TLR4 signaling, the peripheral administration of the TLR2 agonist zymosan only induced hypothermia in TRPM8 KO mice, but caused hypothermia in the early phase and fever in the late phase in WT mice. Therefore, the present study is the first to show that TRPM8 is important for switching between fever and hypothermia under endotoxin-induced inflammation.

$\mathrm{PGE}_{2}$ generates fever by acting on EP3R-expressing neurons in the POA of the hypothalamus ${ }^{35,36}$. The present study showed that the i.c.v. injection of $\mathrm{PGE}_{2}$ generated fever in TRPM8 KO mice in a similar manner to WT mice. TRPM8 KO mice showed normal fever generation by brown adipose tissue with $\beta 3$-adrenergic receptor activation ${ }^{37}$ and cold-induced shivering and tachycardia ${ }^{38}$. These results indicate that heat-generating thermoregulatory effectors are basically normal in TRPM8 KO mice. On the other hand, the i.c.v. injection of LPS induced hypothermia in TRPM8 KO mice, in contrast to fever in WT animals, in the early phase. This hypothermic response following the central injection of LPS was similar to that after the peripheral administration of low-dose LPS. Similarly, the i.c.v. injection of IL-1 $\beta$ appeared to cause hypothermia and did not induce fever in the early phase. The selective deletion of $\mathrm{PGE}_{2}$-synthesizing enzymes in brain endothelial cells strongly attenuated fever responses to peripheral LPS and IL-1 $\beta^{23,39,40}$. A central injection of LPS induced STAT3 signaling in the OVLT and POA to generate fever ${ }^{41}$. Furthermore, a central injection of IL-1 $\beta$ induced NF- $\mathrm{kB}$ signaling in endothelial cells, which is necessary for inducing fever, with 
endothelial cells in the fenestrate capillaries of the OVLT playing the most potent role $^{24}$. The OVLT lacks the BBB and is located close to the central thermoregulatory center, the POA, and, thus, is important for immune-to-brain signaling to initiate systemic inflammation ${ }^{17,42}$. Peripherally administered LPS and zymosan reach TLR4 on astrocytes and TLR2 on microglia and/or macrophages in the OVLT ${ }^{13,43}$. TRPM8-expressing neurons are specifically localized at the POA and $\mathrm{LS}^{30}$. Therefore, TRPM8 in the brain may be involved in switching between fever and hypothermia in the early phase of systemic inflammation.

Fever and hypothermia are controlled alterations in body temperature and correspond to mild and severe forms of systemic inflammation, respectively ${ }^{11}$. Infection-induced hypothermia is accompanied by decreases in the metabolic rate, heat production, and locomotor activity and, thus, hypothermia is a hallmark of severe systemic inflammation ${ }^{44} \cdot \mathrm{PGE}_{2}$ and cytokine levels in plasma and POA are higher in mice exhibiting hypothermia than in fever-generating animals ${ }^{45}$. Fos expression in the PVN and DMH was previously reported to be stronger in mice with hypothermia than in fever-generating animals after the administration of $\operatorname{LPS}^{46}$. In the present study, the number of Fos ${ }^{+}$nuclei was higher in the POA, LS, PVN, and DMH of TRPM8 KO mice than in WT animals after the peripheral administration of low-dose LPS. The activation of the POA-DMH axis was previously shown to be crucial for inducing hypothermia and hypo-metabolism ${ }^{16}$. The PVN has been implicated in sickness behaviors, such as decreases in locomotor activity and food intake $\mathrm{e}^{47,48}$. The present study showed that hypothermic responses were more severe in TRPM8 KO mice than in WT mice following the peripheral administration of high-dose LPS. Furthermore, locomotor activity was significantly lower in TRPM8 KO mice than in WT mice after the administration of high-dose LPS. These results indicate that TRPM8 is necessary for suppressing brain inflammation and, thus, the lack of TRPM8 results in severe neuronal inflammation and, ultimately, hypothermia.

The mechanisms by which TRPM8 controls switching between fever and hypothermia have not yet been elucidated. One explanation is that TRPM8 is necessary for the proper functioning 
of EP3R. The peripheral administration of low-dose LPS caused hypothermia, while that of high-dose LPS elicited more severe hypothermia in EP3R KO mice ${ }^{10}$, which is similar to the present results obtained in TRPM8 KO animals. The present immunohistochemical results showing the expression of TRPM8 in EP3R-expressing neurons in the POA supports this possibility. Another explanation is that TRPM8 suppresses the neural activity of hypothermiainducing POA circuits. The activation of a subpopulation of neurons in the medial and lateral POA acts on the DMH and then induces hypothermia together with decreases in the metabolic rate and locomotor activity ${ }^{14-16}$. Previous findings showing that TRPM8-expressing neurons are localized at the medial and lateral $\mathrm{POA}^{30}$ supports this possibility. However, further analyses are needed to elucidate the significance of central TRPM8 in the control of switching between fever and hypothermia under endotoxin-induced inflammation.

\section{Methods}

Animals. Adult male C57BL/6J mice (8-10 weeks old) were purchased from Japan SLC Inc. (Hamamatsu, Japan) and TRPM8 KO mice were generated by Dr. A. Patapoutian at the Howard Hughes Medical Institute ${ }^{26}$ and supplied by Dr. M. Tominaga at the National Institute of Physiological Sciences. Animals were housed in a colony room with an ambient temperature of $25 \pm 0.5^{\circ} \mathrm{C}$ and a 12-h light/dark cycle; lights on at 7:00 and lights off at 19:00, and were given ad libitum access to commercial chow and tap water. All experiments were performed in accordance with the Guidelines laid down by the NIH and Proper Conduct of Animal Experiments Science Council of Japan. The experimental protocol was approved by the Animal Ethics Experimental Committee of the Kyoto Institute of Technology.

Administration of LPS, zymosan, IL-1ß, and PGE 2. A stock solution of LPS (1 mg/ml; Sigma-Aldrich, 055: type B5), zymosan A from Saccharomyces cerevisiae (FUJIFILM Wako 
Chemical Pure Corporation, Osaka, Japan), IL-1 $\beta$ (R\&D systems, Minneapolis, MN), and PGE 2 (Cayman Chemical, Ann Arbor, MI) were dissolved in pyrogen-free physiological saline (Otsuka Pharmaceutical Co., Ltd.) and stored at $-80^{\circ} \mathrm{C}$. They were diluted with pyrogen-free physiological saline prior to use.

Regarding the peripheral administration of endotoxins, mice were intraperitoneally administered an aliquot of pyrogen-free physiological saline containing low-dose LPS (50 $\mu \mathrm{g} / \mathrm{kg}, 1.25 \mu \mathrm{g} / 300 \mu \mathrm{l})$, high-dose LPS $(5 \mathrm{mg} / \mathrm{kg}, 125 \mu \mathrm{g} / 300 \mu \mathrm{l})$, or zymosan $(3 \mathrm{mg} / \mathrm{kg}, 75$ $\mu \mathrm{g} / 200 \mu \mathrm{l})$. In the i.c.v. administration, a stainless steel cannula (25-gauge) was implanted in each mouse under anesthesia with isoflurane so that the tip was positioned in the lateral cerebral ventricle using a standard stereotaxic technique ${ }^{49} ; 0.3 \mathrm{~mm}$ anteroposterior and $1.0 \mathrm{~mm}$ lateral to the bregma and $2.5 \mathrm{~mm}$ dorsoventral below the skull. A G2 E-mitter transponder (Starr Life Sciences, Oakmont, PA) was implanted one week after cannula surgery. Freely moving mice received an i.c.v. injection ( $3 \mu 1,0.5 \mu \mathrm{l} / \mathrm{min})$ of LPS $(3.6 \mu \mathrm{g} / \mathrm{kg}, 90 \mathrm{ng} / 3 \mu \mathrm{l})$, IL-1 $\beta$ (400 ng/kg; $10 \mathrm{ng} / 3 \mu \mathrm{l})$, low-dose $\mathrm{PGE}_{2}(16 \mathrm{nmol} / \mathrm{kg}, 0.4 \mathrm{nmol} / 3 \mu \mathrm{l})$, high-dose $\mathrm{PGE}_{2}(160 \mathrm{nmol} / \mathrm{kg}, 4$ nmol/3 $\mu \mathrm{l}$ ), or pyrogen-free physiological saline using a Model EP-1000E administration pump (Melquest, Toyama, Japan).

Measurement of body temperature and locomotor activity. Under anesthesia with chloral hydrate, the G2 E-mitter transponder was implanted intraperitoneally to record changes in core body temperature and gross locomotor activity. Mice were then maintained at an ambient temperature of $25^{\circ} \mathrm{C} \pm 0.5^{\circ} \mathrm{C}$ under a 12 -hr light/dark cycle (lights on at 7:00 and lights off at 19:00) for at least 1 week after surgery. Intraperitoneal and i.c.v. administration protocols were initiated at 11:00. Abdominal temperature was measured by biotelemetry at 5-min intervals, and at 1-min intervals for the $\mathrm{PGE}_{2}$ treatment, over a period of $12 \mathrm{hr}$ before and $24 \mathrm{hr}$ after the treatment. Data were acquired and fed to a computer using VitalView software (VitalView series 4000). The baseline temperature was calculated as the mean core body temperature in each 
Scientific Reports

group at 10:45-11:00. The fever index $\left({ }^{\circ} \mathrm{C} \times \mathrm{hr}\right)$ was calculated as the area under the temperature curve according to the baseline temperature before the treatment.

Immunohistochemistry. Mice were perfused intracardially with PBS (pH 7.4) containing $0.1 \%$ trisodium citrate dihydrate followed by $4 \%$ paraformaldehyde (PFA) in $0.1 \mathrm{M}$ phosphate buffer (PB; pH 7.4) under deep anesthesia with isoflurane. Fixed brains were cryoprotected by $30 \%$ sucrose in phosphate-buffered saline (PBS; pH 7.4) and frozen quickly in Tissue-Tek OCT compound (Sakura Finetechnical, Tokyo, Japan). Sections were obtained by a coronal cut on a cryostat (Leica, Wetzlar, Germany) at a thickness of $30 \mu \mathrm{m}$. In immunofluorescent staining, a standard technique was performed on free-floating sections as described in our previous study ${ }^{50}$. In brief, sections were washed with PBS and treated with $25 \mathrm{mM}$ glycine in PBS for 20 min to quench the remaining fixative aldehyde. Sections were preincubated with $5 \%$ normal goat serum (NGS) in PBS containing 0.3\% Triton X-100 (PBST) at $4^{\circ} \mathrm{C}$ for $24 \mathrm{hr}$ and then incubated with the primary antibody in PBST containing $1 \% \mathrm{NGS}$ at $4^{\circ} \mathrm{C}$ for $72 \mathrm{hr}$. The following primary antibodies were used: a goat polyclonal antibody against EP3R (KO-2017; dilution 1:50) and a rabbit polyclonal antibody against Fos (Cat. No. sc-52, Santa Cruz Biotechnology, Santa Cruz, CA; dilution 1:3,000). The anti-EP3R antibody was generated using the $\mathrm{N}$-terminal amino acid sequence of mouse EP3R (residues 2-28; ASMWAPEHSAEAHSNLSSTTDDCGSVS) according to a previous study ${ }^{51}$. After several washes with PBST, they were further incubated with an Alexa 488- or 594-conjugated secondary goat antibody (Jackson ImmunoResearch, dilution 1:400). Regarding nuclear staining, sections were incubated with 4',6-diamidino-2phenylindole dihydrochloride solution (DAPI; Dojindo, Kumamoto, Japan; dilution 1:1,000).

Fluorescent microscopic observations. In fluorescent microscopic observations, coverslips were sealed with Vectashield (Vector Labs, Burlingame, CA) and observations were performed using a fluorescent microscope (AxioScope. 5, Carl Zeiss, Oberkochen, Germany). We selected 
at least 5 sections per animal from the POA (between the bregma 0.26 and $0.74 \mathrm{~mm}$ ), LS (between the bregma 1.02 and $0.38 \mathrm{~mm}$ ), PVN (between the bregma -0.74 and $-0.94 \mathrm{~mm}$ ), and DMH (between the bregma -1.46 and $-2.06 \mathrm{~mm}$ ) according to the mouse brain atlas (Paxinos \& Franklin, 2001). To perform a quantitative analysis, fluorescent images were obtained using a DS-Fi3 digital microscope camera (Nikon, Tokyo, Japan) under the same pinhole size, brightness, and contrast settings. Images $(1,440 \times 1,024$ pixels $)$ were saved as TIF files $(1,440$ $\times 1,024$ pixels) by employing NIS Elements BR (Nikon) and arranged using Photoshop CC (Adobe Systems Incorporated, San Jose, CA). In quantitative analyses, the total area of each brain region was measured using Image $\mathrm{J}^{52}$. The numbers of $\mathrm{Fos}^{+}$nuclei were counted using ImageJ, the threshold intensity of which was set to include measurement profiles by visual inspections and was kept constant. An analysis of all images was performed such that the experimenter was blind to the treatment group.

\section{Declaration of interest}

The authors declare that there is no conflict of interest that may be perceived as prejudicing the impartiality of the research reported.

\section{AUTHOR CONTRIBUTIONS}

CS performed experiments for Figs. 1, 3 4, 5, and 6d-f and analyzed the data. RH performed immunohistochemistry and analyzed the data for Fig. 7 and 8. MF conducted the experiment for Fig. 2 and analyzed the data and KO conducted the experiment for Fig. 6a-c. EK helped with some experiments and prepared some figures. SM designed and supervised the project, finalized all figures, and wrote manuscript.

\section{FUNDING}

This work was supported in part by Scientific Research Grants from The Japan Society for the 
Scientific Reports

Promotion of Science (16K07027, 19K06921). 


\section{Figure legends}

Fig. 1 Effects of the intraperitoneal administration of a low dose of the TLR4 agonist, LPS, on the abdominal core temperature and locomotor activity of WT and TRPM8 KO mice. The body temperature and locomotor activity of mice were measured with a G2 E-mitter transponder at an ambient temperature of $25 \pm 0.5^{\circ} \mathrm{C}$ after the intraperitoneal administration of $50 \mu \mathrm{g} / \mathrm{kg} \mathrm{LPS}$. a: The administration of LPS caused hypothermia in TRPM8 KO mice, whereas it induced fever in WT mice. b: The temperature index of LPS-treated TRPM8 KO mice was negative, whereas that of LPS-treated WT animals was positive. c: Cumulative locomotor activity did not significantly differ among groups. Data (WT saline, $\mathrm{n}=9$; WT LPS, $\mathrm{n}=6$; TRPM8 KO saline, $\mathrm{n}=5$; TRPM8 KO LPS, $\mathrm{n}=11)$ are expressed as the mean $( \pm$ s.e.m.). Lines in a indicate a significant duration $(p<0.05) . * * p<0.01$ among groups by a one-way ANOVA with Tukey's post hoc test.

Fig. 2 Effects of the intraperitoneal administration of a high dose of the TLR4 agonist, LPS, on the abdominal core temperature and locomotor activity of WT and TRPM8 KO mice. Animals were intraperitoneally administered $5 \mathrm{mg} / \mathrm{kg}$ LPS and body temperature and locomotor activity were measured with a G2 E-mitter transponder at an ambient temperature of $25 \pm 0.5^{\circ} \mathrm{C}$. $\mathbf{a}$ : The body temperature of WT and TRPM8 KO mice intraperitoneally administered $5 \mathrm{mg} / \mathrm{kg}$ LPS was significantly lower than that of mice administered saline, whereas the core body temperature of TRPM8 KO mice was significantly lower than that of WT animals following the administration of LPS. b: The temperature index was significantly lower in LPS-treated TRPM8 KO mice than in LPS-treated WT mice. c,d: The cumulative locomotor activity of LPS-treated TRPM8 KO mice during all periods examined was markedly lower than that of the saline controls, whereas that of LPS-treated WT animals did not show any significant decrease. Data (WT saline, $\mathrm{n}=$ 9; WT LPS, $\mathrm{n}=6$; TRPM8 KO saline, $\mathrm{n}=5$; TRPM8 KO LPS, $\mathrm{n}=9$ ) are 
expressed as the mean ( \pm s.e.m.). Lines in $\mathbf{a}$ indicate a significant period $(p<0.05) .{ }^{*} p<0.05$, ** $p<0.01, * * * p<0.001$ among groups by a one-way ANOVA with Tukey's post hoc test.

Fig. 3 Effects of an i.c.v injection of the TLR4 agonist, LPS, on the abdominal core temperature and locomotor activity of WT and TRPM8 KO mice. Mice received an i.c.v. injection of 3.6 $\mu \mathrm{g} / \mathrm{kg}$ LPS and body temperature and locomotor activity were measured with a G2 E-mitter transponder at an ambient temperature of $25 \pm 0.5^{\circ} \mathrm{C}$. a: The i.c.v. injection of LPS induced prominent fever in WT mice throughout the period examined. In contrast, the LPS injection caused hypothermia in TRPM8 KO mice between 1.5 and $3.0 \mathrm{hr}$ after the injection. Body temperature in TRPM8 KO animals then gradually increased from $3.0 \mathrm{hr}$ and they developed fever after $4 \mathrm{hr}$. b: The temperature index of LPS-injected TRPM8 KO mice was negative during the early phase (0 3.5 hr), whereas that of LPS-injected WT animals was positive. The temperature index of LPS-injected WT and TRPM8 KO mice was positive in the late phase (3.5 8.0 hr). c: Cumulative locomotor activity was not significantly different among groups. Data (WT saline, $\mathrm{n}=6$; WT LPS, $\mathrm{n}=6$; TRPM8 KO saline, $\mathrm{n}=7$; TRPM8 KO LPS, $\mathrm{n}=6$ ) are expressed as the mean ( \pm s.e.m.). Lines in $\mathbf{a}$ indicate a significant period $(p<0.05) .{ }^{*} p<0.05$, ** $p<0.01$ among groups by a one-way ANOVA with Tukey’s post hoc test.

Fig. 4 Effects of the intraperitoneal administration of the TLR2 agonist, zymosan, on the abdominal core temperature and locomotor activity of WT and TRPM8 KO mice. Body temperature and locomotor activity were measured with a G2 E-mitter transponder at an ambient temperature of $25 \pm 0.5{ }^{\circ} \mathrm{C}$ after the intraperitoneal administration of $10 \mathrm{mg} / \mathrm{kg}$ zymosan. a: The intraperitoneal administration of zymosan initially caused hypothermia and then induced fever in WT mice. However,TRPM8 KO mice exhibited hypothermia and did not show fever. b: The temperature index was significantly lower in LPS-injected TRPM8 KO mice in both the early $(0 \sim 1.5)$ and late $(1.5 \sim 3 \mathrm{hr})$ phases than in WT mice. The temperature index 
of both LPS-injected WT and TRPM8 KO mice was negative in the early phase, whereas that of LPS-injected WT and TRPM8 KO animals was positive and negative, respectively, in the late phase. c: Cumulative locomotor activity was not significantly different among groups. Data (WT saline, $\mathrm{n}=9$; WT zymosan, $\mathrm{n}=5$; TRPM8 KO saline, $\mathrm{n}=5$; TRPM8 KO zymosan, $\mathrm{n}=4$ ) are expressed as the mean ( \pm s.e.m. $)$. Lines in $\mathbf{a}$ indicate a significant duration $(p<0.05) .{ }^{*} p<$ $0.05, * * p<0.01$ among groups by a one-way ANOVA with Tukey's post hoc test.

Fig. 5 Effects of an i.c.v injection of IL-1 $\beta$ on the abdominal core temperature and locomotor activity of WT and TRPM8 KO mice. Mice received an i.c.v. injection of $400 \mathrm{ng} / \mathrm{kg}$ IL-1 $\beta$ and body temperature and locomotor activity were measured with a G2 E-mitter transponder at an ambient temperature of $25 \pm 0.5^{\circ} \mathrm{C}$. a: The i.c.v. injection of IL-1 $\beta$ induced fever in WT mice, but not in their saline controls, whereas TRPM8 KO mice did not show fever in the early phase $(0 \sim 3 \mathrm{hr})$, but developed fever in the late phase $(3 \sim 8 \mathrm{hr})$. b: The temperature index was significantly different between WT and TRPM8 KO mice in the early phase following the IL$1 \beta$ injection, but not in the late phase. $\mathbf{c}$ : Cumulative locomotor activity was not significantly different among groups. Data (WT saline, $\mathrm{n}=6$; WT IL-1 $\beta, \mathrm{n}=6$; TRPM8 KO saline, $\mathrm{n}=7$; TRPM8 KO Pam3CSK4, $\mathrm{n}=4$ ) are expressed as the mean ( \pm s.e.m.). Lines in a indicate a significant time $(p<0.05)$. ${ }^{* *} p<0.01$ among groups by a one-way ANOVA with Tukey's post hoc test.

Fig. 6 Colocalization of TRPM8 and EP3R in the POA and LS and effects of an i.c.v injection of $\mathrm{PGE}_{2}$ on the abdominal core temperature and locomotor activity of WT and TRPM8 KO mice. Cryosections were immunostained with GFP and EP3R in TRPM8 KO mice with EGFP knocked in at the start codon of TRPM8, resulting in the expression of EGFP instead of TRPM8. a-c: EGFP-expressing TRPM8 neurons (arrowheads) often expressed EP3R in the POA (a). A 3D analysis showed the colocalization of EGFP and EP3R (b). The majority of EGFP- 
expressing TRPM8 neurons very weakly expressed EP3R in the LS. Scale bars = 50 (a), 10 (b) $\mu \mathrm{m}$. d: Mice received an i.c.v. injection of 16 or $160 \mathrm{nmol} / \mathrm{kg} \mathrm{PGE}_{2}$ and body temperature and locomotor activity were measured with a G2 E-mitter transponder at an ambient temperature of $25 \pm 0.5^{\circ} \mathrm{C}$. The i.c.v. injection of $\mathrm{PGE}_{2}$ induced prominent fever in both $\mathrm{WT}$ and TRPM8 KO mice. e: The temperature index was significantly increased in WT and TRPM8 KO mice by the i.c.v. injection of $\mathrm{PGE}_{2}$. f: Cumulative locomotor activity was not significantly different among groups. Data (WT: saline, $\mathrm{n}=6 ; 16 \mathrm{nmol} / \mathrm{kg} \mathrm{PGE}_{2}, \mathrm{n}=4 ; 160 \mathrm{nmol} / \mathrm{kg} \mathrm{PGE}_{2}, \mathrm{n}=4$; TRPM8 KO: saline, $\left.\mathrm{n}=7 ; 16 \mathrm{nmol} / \mathrm{kg} \mathrm{PGE}_{2}, \mathrm{n}=5 ; 160 \mathrm{nmol} / \mathrm{kg} \mathrm{PGE}_{2}\right)$ are expressed as the mean $( \pm$ s.e.m.). Lines in $\mathbf{d}$ indicate a significant period $(p<0.05) .{ }^{*} p<0.05,{ }^{*} p<0.01$ among groups by a one-way ANOVA with Tukey's post hoc test.

Fig. 7. Effects of the intraperitoneal administration of a low dose of the TLR4 agonist, LPS, on Fos expression in the POA and LS of WT and TRPM8 KO mice. Animals were intraperitoneally administered $50 \mu \mathrm{g} / \mathrm{kg}$ LPS and were then sacrificed for Fos immunohistochemistry 2 hours after the injection. a-d, a-d': Fluorescent images revealed many $\mathrm{Fos}^{+}$nuclei in the POA and LS of both WT and TRPM8 KO mice. e: The number of Fos ${ }^{+}$nuclei in the LSD, LSI, BST, and MPA was significantly higher in LPS-treated TRPM8 KO mice than in WT mice. Data $(n=4)$ were expressed as the mean \pm s.e.m. ${ }^{*}: \mathrm{P}<0.05,{ }^{* *}: \mathrm{P}<0.01, * * *: \mathrm{P}<0.01$ vs control WT mice. Statistical analyses were performed using the Student's $t$-test.

Fig. 8. Effects of the intraperitoneal administration of a low dose of the TLR4 agonist, LPS, on Fos expression in the PVN and DMH of WT and TRPM8 KO mouse. Animals were intraperitoneally administered $50 \mu \mathrm{g} / \mathrm{kg}$ LPS and were then sacrificed for Fos immunohistochemistry 2 hours after the injection. a-d, a-d': Fluorescent images revealed many Fos $^{+}$nuclei in the PVN and DMH of both WT and TRPM8 KO mice. e: The number of Fos ${ }^{+}$ nuclei in the PVN and DMH was significantly higher in LPS-treated TRPM8 KO mice than in 
Scientific Reports

WT mice. Data $(\mathrm{n}=4)$ were expressed as the mean \pm s.e.m. $*$ : $\mathrm{P}<0.05, * *$ : $\mathrm{P}<0.01, * * *: \mathrm{P}<$

0.01 vs control WT mice. Statistical analyses were performed using the Student's $t$-test. 


\section{References}

1 Thaiss, C. A., Zmora, N., Levy, M. \& Elinav, E. The microbiome and innate immunity. Nature 535, 65-74, doi:10.1038/nature18847 (2016).

2 Beutler, B. A. TLRs and innate immunity. Blood 113, 1399-1407, doi:10.1182/blood-200807-019307 (2009).

3 Lemaitre, B., Nicolas, E., Michaut, L., Reichhart, J. M. \& Hoffmann, J. A. The dorsoventral regulatory gene cassette spatzle/Toll/cactus controls the potent antifungal response in Drosophila adults. Cell 86, 973-983, doi:10.1016/s0092-8674(00)80172-5 (1996).

McCusker, R. H. \& Kelley, K. W. Immune-neural connections: how the immune system's response to infectious agents influences behavior. $J$ Exp Biol 216, 84-98, doi:10.1242/jeb.073411 (2013).

5 Schulman, C. I. et al. The effect of antipyretic therapy upon outcomes in critically ill patients: a randomized, prospective study. Surg Infect (Larchmt) 6, 369-375, doi:10.1089/sur.2005.6.369 (2005).

6 Evans, S. S., Repasky, E. A. \& Fisher, D. T. Fever and the thermal regulation of immunity: the immune system feels the heat. Nat Rev Immunol 15, 335-349, doi:10.1038/nri3843 (2015).

7 Kluger, M. J. Phylogeny of fever. Fed Proc 38, 30-34 (1979).

8 Romanovsky, A. A., Shido, O., Sakurada, S., Sugimoto, N. \& Nagasaka, T. Endotoxin shock: thermoregulatory mechanisms. Am $J$ Physiol 270, R693-703, doi:10.1152/ajpregu.1996.270.4.R693 (1996).

9 Liu, E. et al. Naturally occurring hypothermia is more advantageous than fever in severe forms of lipopolysaccharide- and Escherichia coli-induced systemic inflammation. Am $J$ Physiol Regul Integr Comp Physiol 302, R1372-1383, doi:10.1152/ajpregu.00023.2012 (2012).

10 Oka, T. et al. Characteristics of thermoregulatory and febrile responses in mice deficient in prostaglandin EP1 and EP3 receptors. $J$ Physiol 551, 945-954, doi:10.1113/jphysiol.2003.048140 (2003).

11 Garami, A., Steiner, A. A. \& Romanovsky, A. A. Fever and hypothermia in systemic inflammation. Handb Clin Neurol 157, 565-597, doi:10.1016/B978-0-444-64074-1.00034-3 (2018).

12 Bastos-Pereira, A. L. et al. Involvement of brain cytokines in zymosan-induced febrile response. J Appl Physiol (1985) 116, 1220-1229, doi:10.1152/japplphysiol.01278.2013 (2014).

13 Takagi, S. et al. Depletion of microglia and macrophages with clodronate liposomes attenuates zymosan-induced Fos expression and hypothermia in the adult mouse. $J$ Neuroimmunol 344, 577244, doi:10.1016/j.jneuroim.2020.577244 (2020).

14 Hrvatin, S. et al. Neurons that regulate mouse torpor. Nature 583, 115-121, doi:10.1038/s41586-020-2387-5 (2020). 
15 Zhang, K. X. et al. Violet-light suppression of thermogenesis by opsin 5 hypothalamic neurons. Nature 585, 420-425, doi:10.1038/s41586-020-2683-0 (2020).

Takahashi, T. M. et al. A discrete neuronal circuit induces a hibernation-like state in rodents. Nature 583, 109-114, doi:10.1038/s41586-020-2163-6 (2020).

Miyata, S. New aspects in fenestrated capillary and tissue dynamics in the sensory circumventricular organs of adult brains. Front Neurosci 9, 390, doi:10.3389/fnins.2015.00390 (2015).

18 Siso, S., Jeffrey, M. \& Gonzalez, L. Sensory circumventricular organs in health and disease. Acta Neuropathol 120, 689-705, doi:10.1007/s00401-010-0743-5 (2010).

19 McKinley, M. J. et al. The sensory circumventricular organs of the mammalian brain. Adv Anat Embryol Cell Biol 172, III-XII, 1-122, back cover, doi:10.1007/978-3-642-55532-9 (2003).

20 Nakano, Y. et al. Astrocytic TLR4 expression and LPS-induced nuclear translocation of STAT3 in the sensory circumventricular organs of adult mouse brain. J Neuroimmunol 278, 144-158, doi:10.1016/j.jneuroim.2014.12.013 (2015).

21 Murayama, S., Kurganov, E. \& Miyata, S. Activation of microglia and macrophages in the circumventricular organs of the mouse brain during TLR2-induced fever and sickness responses. J Neuroimmunol 334, 576973, doi:10.1016/j.jneuroim.2019.576973 (2019).

Muneoka, S., Murayama, S., Nakano, Y. \& Miyata, S. TLR4 in circumventricular neural stem cells is a negative regulator for thermogenic pathways in the mouse brain. $J$ Neuroimmunol 331, 58-73, doi:10.1016/j.jneuroim.2018.04.017 (2019).

23 Wilhelms, D. B. et al. Deletion of prostaglandin E2 synthesizing enzymes in brain endothelial cells attenuates inflammatory fever. $J$ Neurosci 34, 11684-11690, doi:10.1523/JNEUROSCI.1838-14.2014 (2014).

24 Knoll, J. G., Krasnow, S. M. \& Marks, D. L. Interleukin-1beta signaling in fenestrated capillaries is sufficient to trigger sickness responses in mice. J Neuroinflammation 14, 219, doi:10.1186/s12974-017-0990-7 (2017).

25 McKemy, D. D., Neuhausser, W. M. \& Julius, D. Identification of a cold receptor reveals a general role for TRP channels in thermosensation. Nature 416, 52-58, doi:10.1038/nature719 (2002).

26 Dhaka, A. et al. TRPM8 is required for cold sensation in mice. Neuron 54, 371-378, doi:10.1016/j.neuron.2007.02.024 (2007).

27 Knowlton, W. M. et al. A sensory-labeled line for cold: TRPM8-expressing sensory neurons define the cellular basis for cold, cold pain, and cooling-mediated analgesia. J Neurosci 33, 2837-2848, doi:10.1523/JNEUROSCI.1943-12.2013 (2013).

28 Ran, C., Hoon, M. A. \& Chen, X. The coding of cutaneous temperature in the spinal cord. Nat Neurosci 19, 1201-1209, doi:10.1038/nn.4350 (2016).

29 Yarmolinsky, D. A. et al. Coding and Plasticity in the Mammalian Thermosensory System. Neuron 92, 1079-1092, doi:10.1016/j.neuron.2016.10.021 (2016). 
30 Ordas, P. et al. Expression of the cold thermoreceptor TRPM8 in rodent brain thermoregulatory circuits. J Comp Neurol, doi:10.1002/cne.24694 (2019).

31 Bautista, D. M. et al. The menthol receptor TRPM8 is the principal detector of environmental cold. Nature 448, 204-208, doi:10.1038/nature05910 (2007).

32 Ramachandran, R. et al. TRPM8 activation attenuates inflammatory responses in mouse models of colitis. Proc Natl Acad Sci US A 110, 7476-7481, doi:10.1073/pnas.1217431110 (2013).

33 Ewanchuk, B. W., Allan, E. R. O., Warren, A. L., Ramachandran, R. \& Yates, R. M. The cooling compound icilin attenuates autoimmune neuroinflammation through modulation of the T-cell response. FASEB J 32, 1236-1249, doi:10.1096/fj.201700552R (2018).

Liu, H., Hua, L., Liu, Q., Pan, J. \& Bao, Y. Cold Stimuli Facilitate Inflammatory Responses Through Transient Receptor Potential Melastatin 8 (TRPM8) in Primary Airway Epithelial Cells of Asthmatic Mice. Inflammation 41, 1266-1275, doi:10.1007/s10753-018-0774-y (2018).

35 Scammell, T. E., Elmquist, J. K., Griffin, J. D. \& Saper, C. B. Ventromedial preoptic prostaglandin E2 activates fever-producing autonomic pathways. J Neurosci 16, 6246-6254 (1996).

36 Lazarus, M. et al. EP3 prostaglandin receptors in the median preoptic nucleus are critical for fever responses. Nat Neurosci 10, 1131-1133, doi:10.1038/nn1949 (2007).

37 Reimundez, A. et al. Deletion of the Cold Thermoreceptor TRPM8 Increases Heat Loss and Food Intake Leading to Reduced Body Temperature and Obesity in Mice. J Neurosci 38, 3643-3656, doi:10.1523/JNEUROSCI.3002-17.2018 (2018).

38 Feketa, V. V., Balasubramanian, A., Flores, C. M., Player, M. R. \& Marrelli, S. P. Shivering and tachycardic responses to external cooling in mice are substantially suppressed by TRPV1 activation but not by TRPM8 inhibition. Am J Physiol Regul Integr Comp Physiol 305, R1040-1050, doi:10.1152/ajpregu.00296.2013 (2013).

39 Engstrom, L. et al. Lipopolysaccharide-induced fever depends on prostaglandin E2 production specifically in brain endothelial cells. Endocrinology 153, 4849-4861, doi:10.1210/en.2012-1375 (2012).

40 Eskilsson, A. et al. Immune-Induced Fever Is Dependent on Local But Not Generalized Prostaglandin E2 Synthesis in the Brain. $J$ Neurosci 37, 5035-5044, doi:10.1523/JNEUROSCI.3846-16.2017 (2017).

41 Yoshida, A. et al. TRPV1 is crucial for proinflammatory STAT3 signaling and thermoregulation-associated pathways in the brain during inflammation. Sci Rep 6, 26088, doi:10.1038/srep26088 (2016).

42 Roth, J., Harre, E. M., Rummel, C., Gerstberger, R. \& Hubschle, T. Signaling the brain in systemic inflammation: role of sensory circumventricular organs. Front Biosci 9, 290-300 (2004).

43 Vargas-Caraveo, A. et al. Lipopolysaccharide enters the rat brain by a lipoprotein-mediated 
Scientific Reports

transport mechanism in physiological conditions. Sci Rep 7, 13113, doi:10.1038/s41598-01713302-6 (2017).

44 Romanovsky, A. A. et al. Fever and hypothermia in systemic inflammation: recent discoveries and revisions. Front Biosci 10, 2193-2216, doi:10.2741/1690 (2005).

45 Saramago, E. A. et al. Molecular hydrogen potentiates hypothermia and prevents hypotension and fever in LPS-induced systemic inflammation. Brain Behav Immun 75, 119128, doi:10.1016/j.bbi.2018.09.027 (2019).

46 Wanner, S. P. et al. Lipopolysaccharide-induced neuronal activation in the paraventricular and dorsomedial hypothalamus depends on ambient temperature. PLoS One 8, e75733, doi:10.1371/journal.pone.0075733 (2013).

47 Matsuoka, Y. et al. Impaired adrenocorticotropic hormone response to bacterial endotoxin in mice deficient in prostaglandin E receptor EP1 and EP3 subtypes. Proc Natl Acad Sci U $S A$ 100, 4132-4137, doi:10.1073/pnas.0633341100 (2003).

48 Frenois, F. et al. Lipopolysaccharide induces delayed FosB/DeltaFosB immunostaining within the mouse extended amygdala, hippocampus and hypothalamus, that parallel the expression of depressive-like behavior. Psychoneuroendocrinology 32, 516-531, doi:10.1016/j.psyneuen.2007.03.005 (2007).

49 Paxinos, G. \& Franklin, K. The Mouse Brain in Stereotaxic Coordinates. (Academic Press, San Diego, 2007).

50 Furube, E., Kawai, S., Inagaki, H., Takagi, S. \& Miyata, S. Brain Region-dependent Heterogeneity and Dose-dependent Difference in Transient Microglia Population Increase during Lipopolysaccharide-induced Inflammation. Sci Rep 8, 2203, doi:10.1038/s41598-01820643-3 (2018).

51 Nakamura, K. et al. Immunohistochemical localization of prostaglandin EP3 receptor in the rat nervous system. $J$ Comp Neurol 421, 543-569, doi:10.1002/(sici)10969861(20000612)421:4<543::aid-cne6>3.0.co;2-3 (2000).

52 Schneider, C. A., Rasband, W. S. \& Eliceiri, K. W. NIH Image to ImageJ: 25 years of image analysis. Nat Methods 9, 671-675, doi:10.1038/nmeth.2089 (2012). 
Figure 1

a
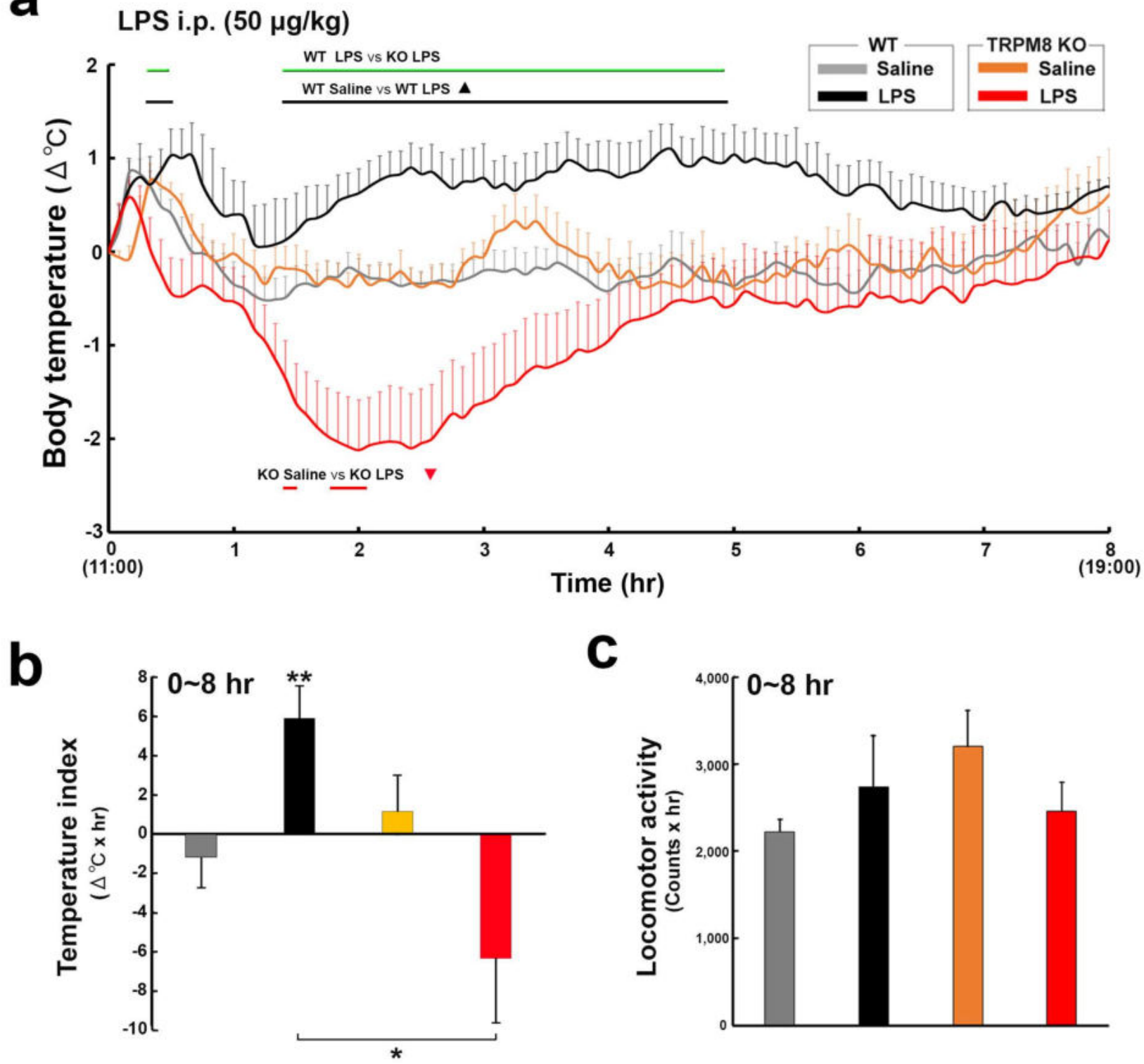

C

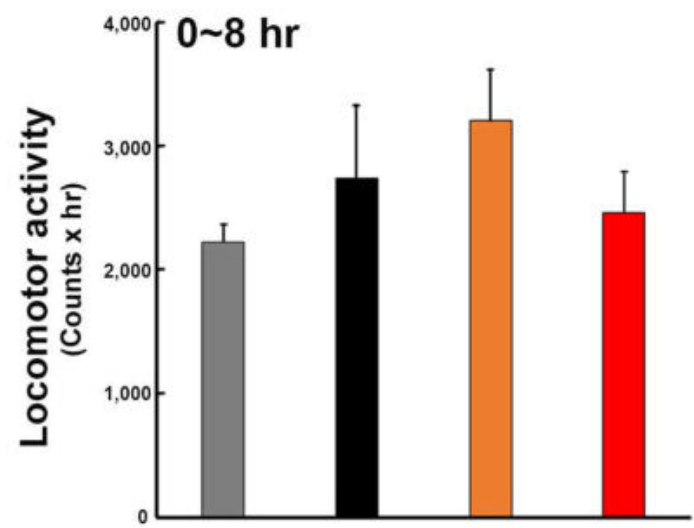


Figure 2

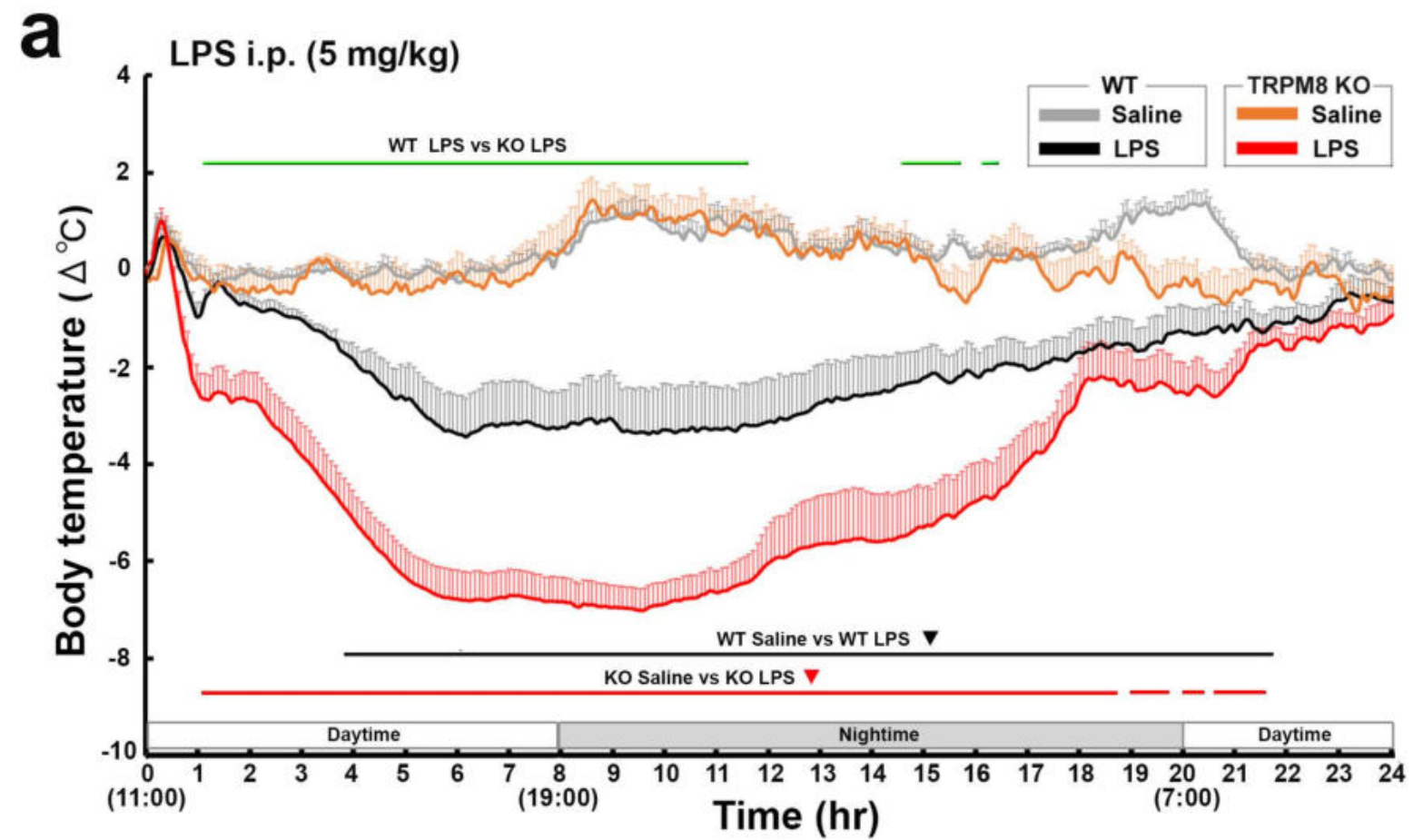

b
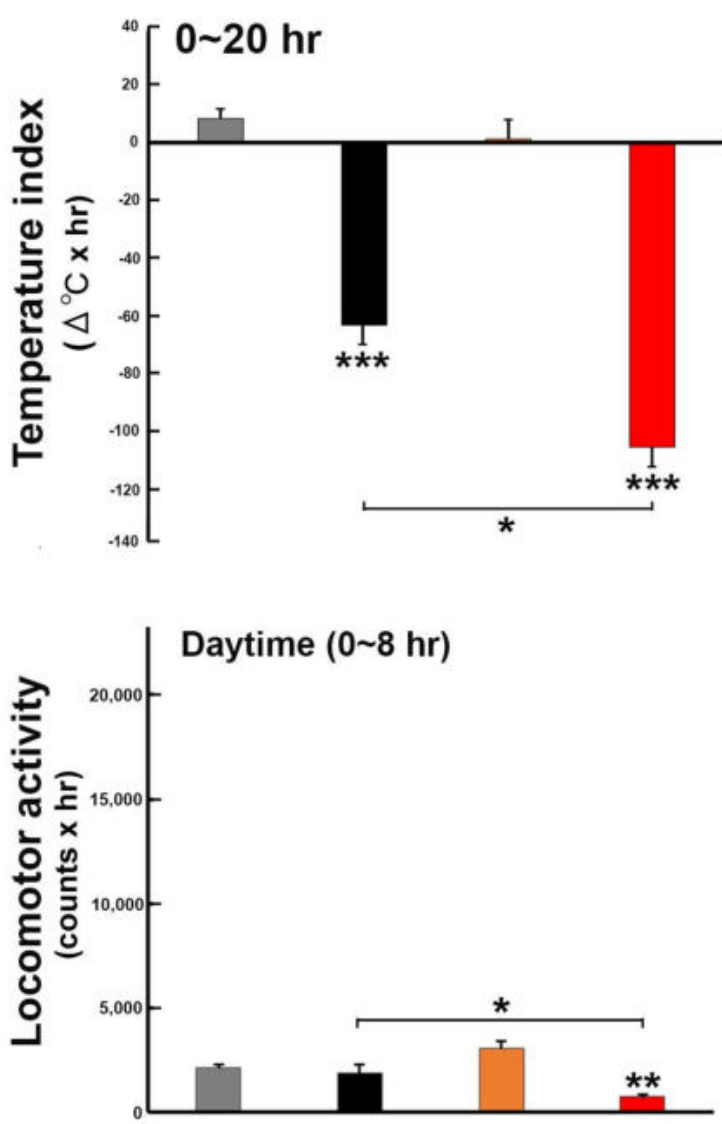

C $\quad 0 \sim 20 \mathrm{hr}$
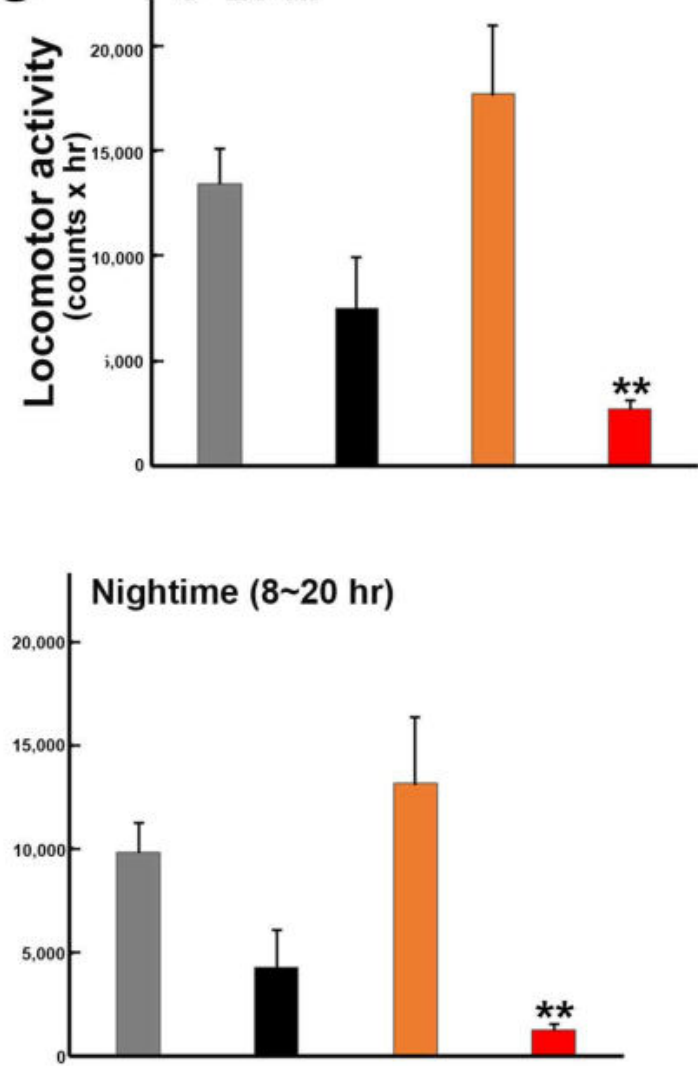
a
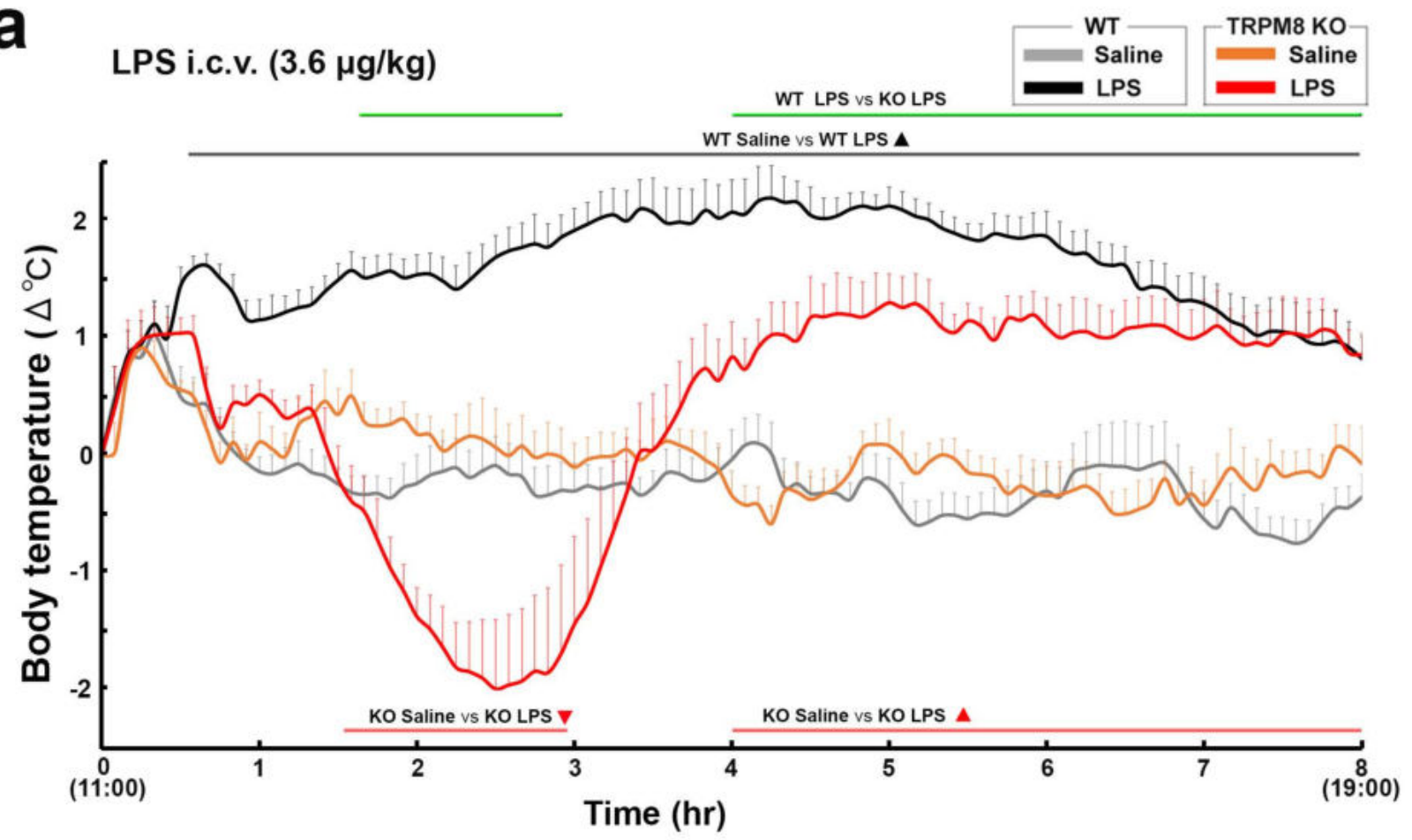

b
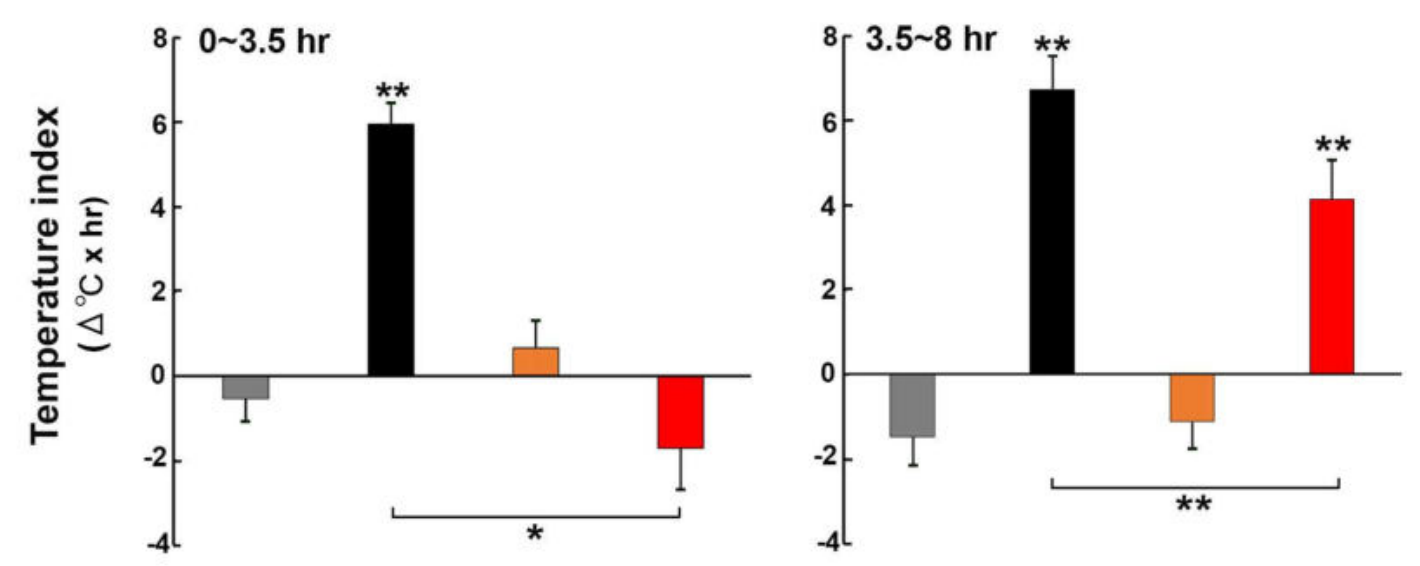

C
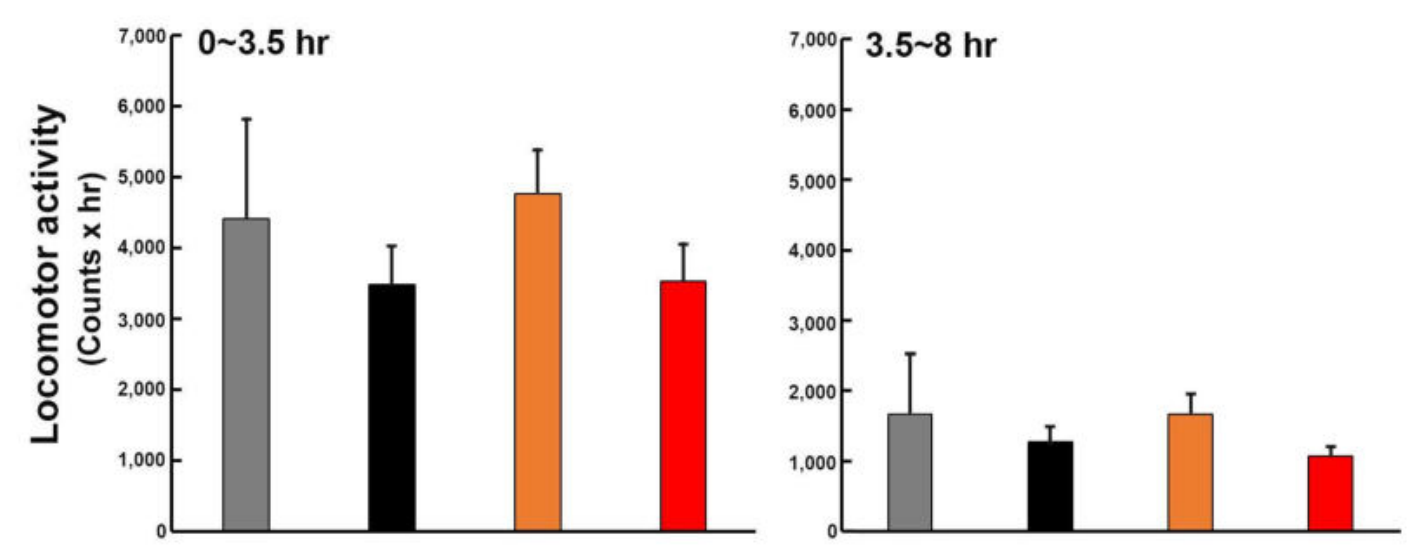
Figure 4

a

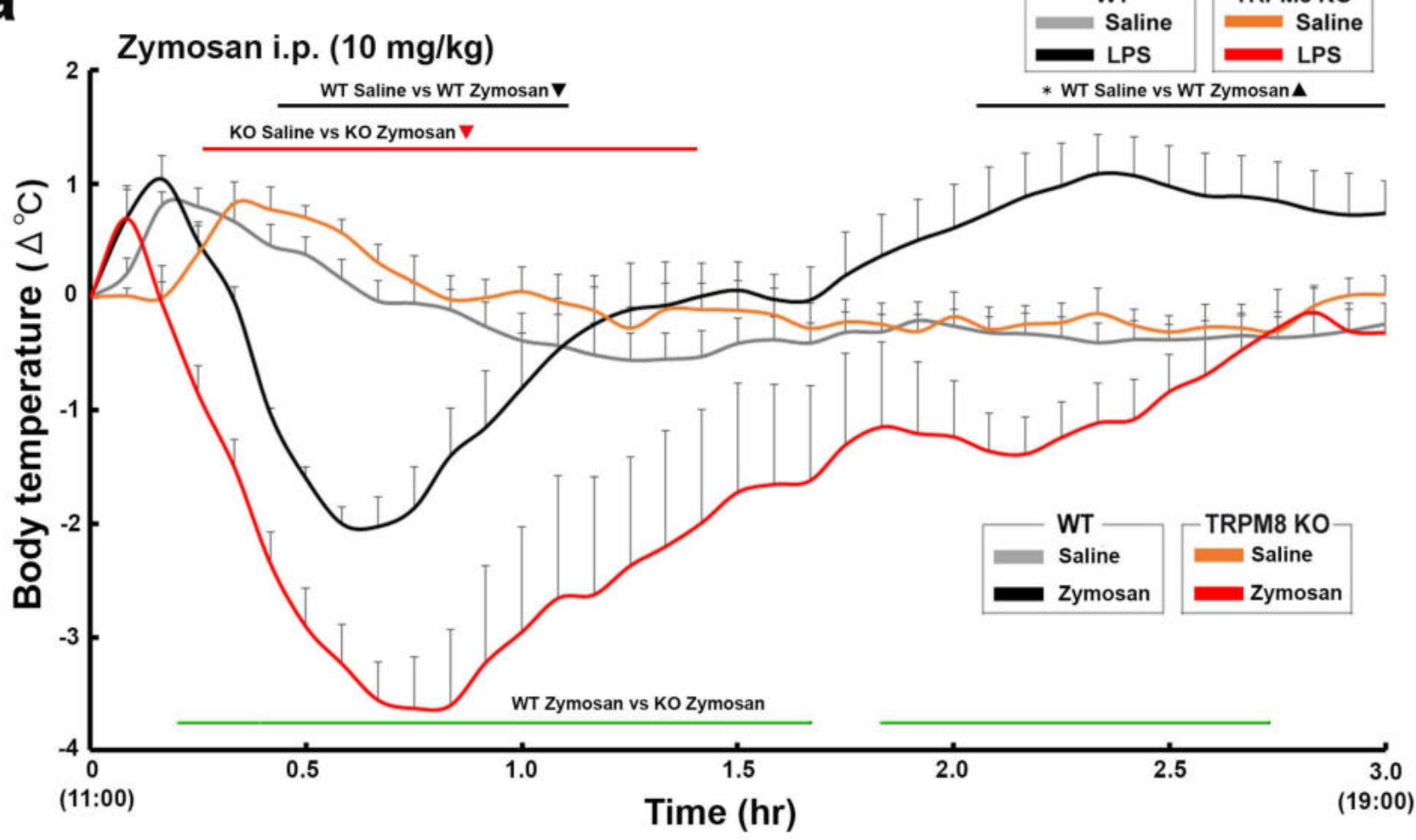

b
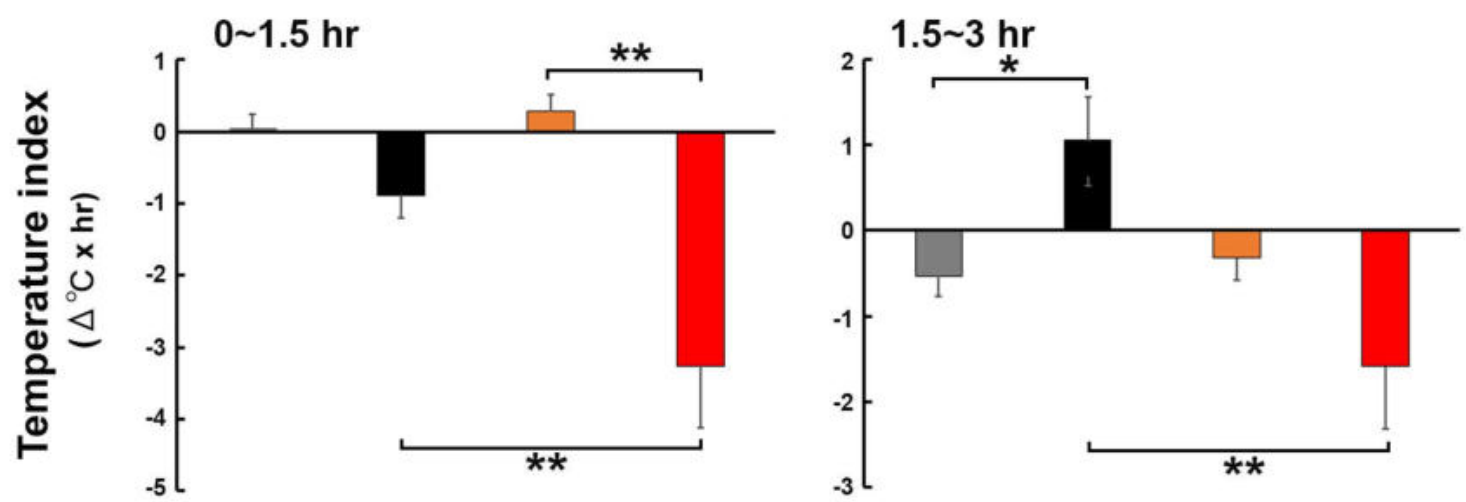

C
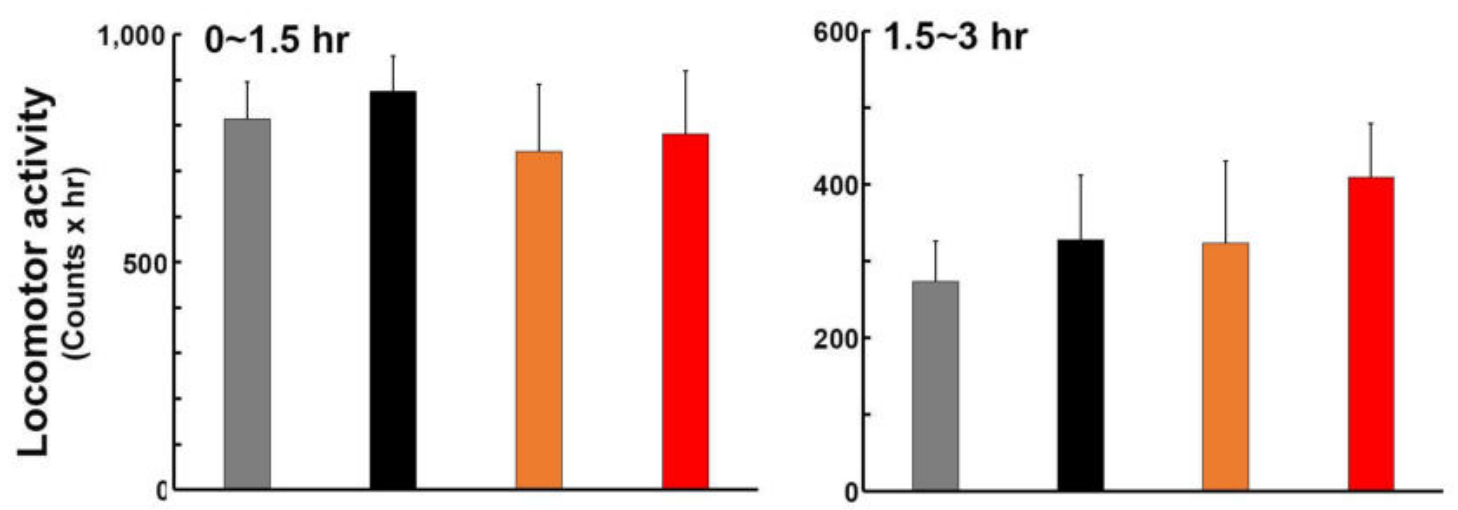
Figure 5

a

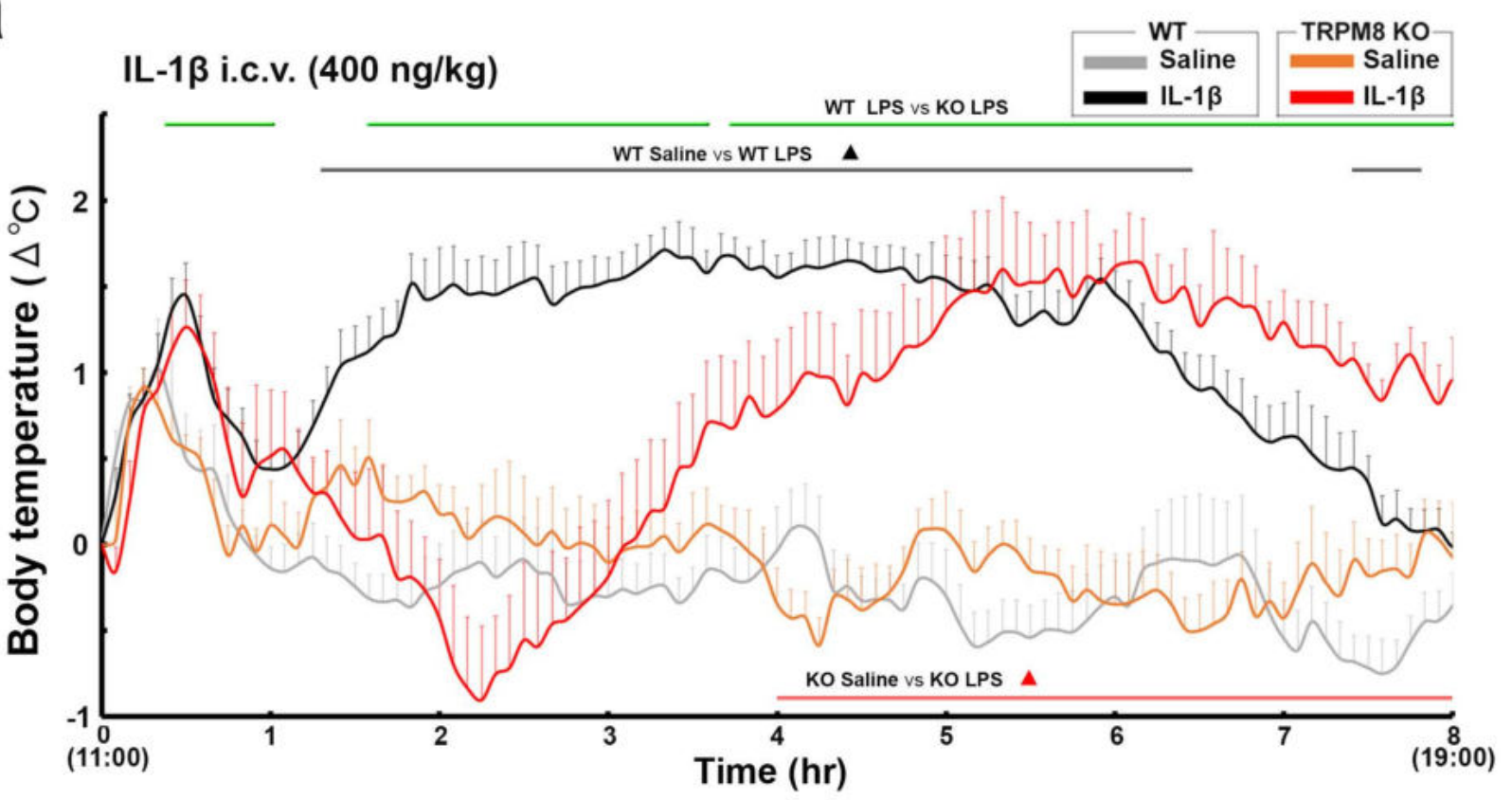

b
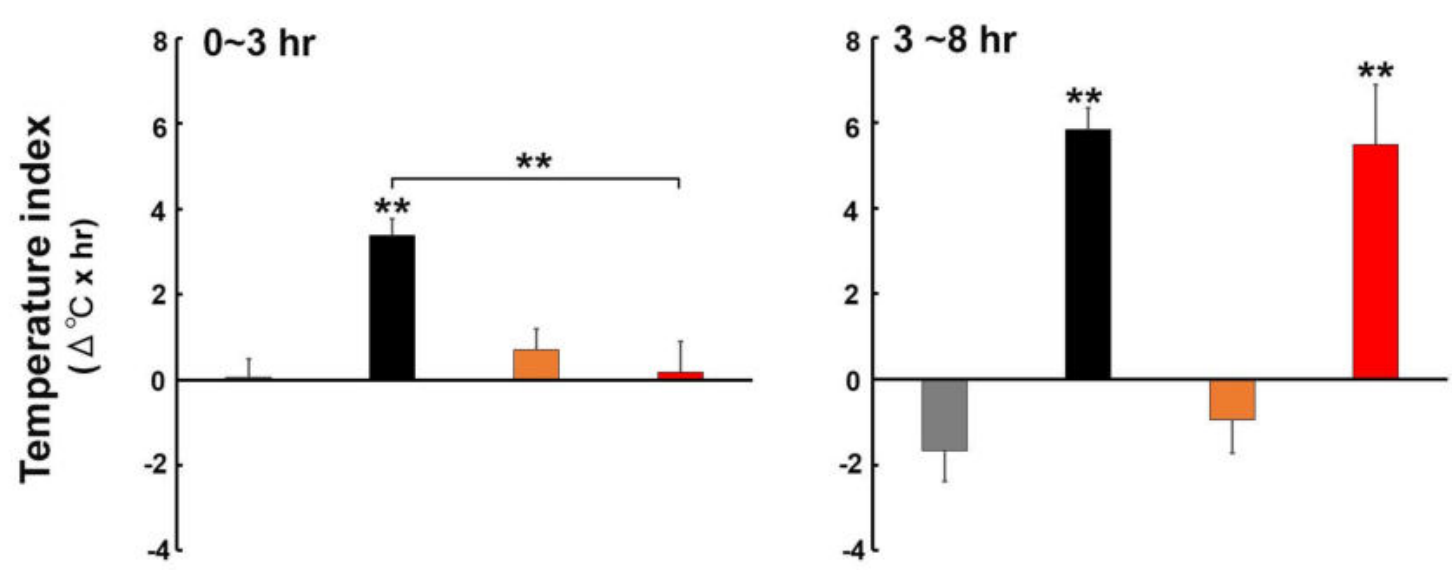

C
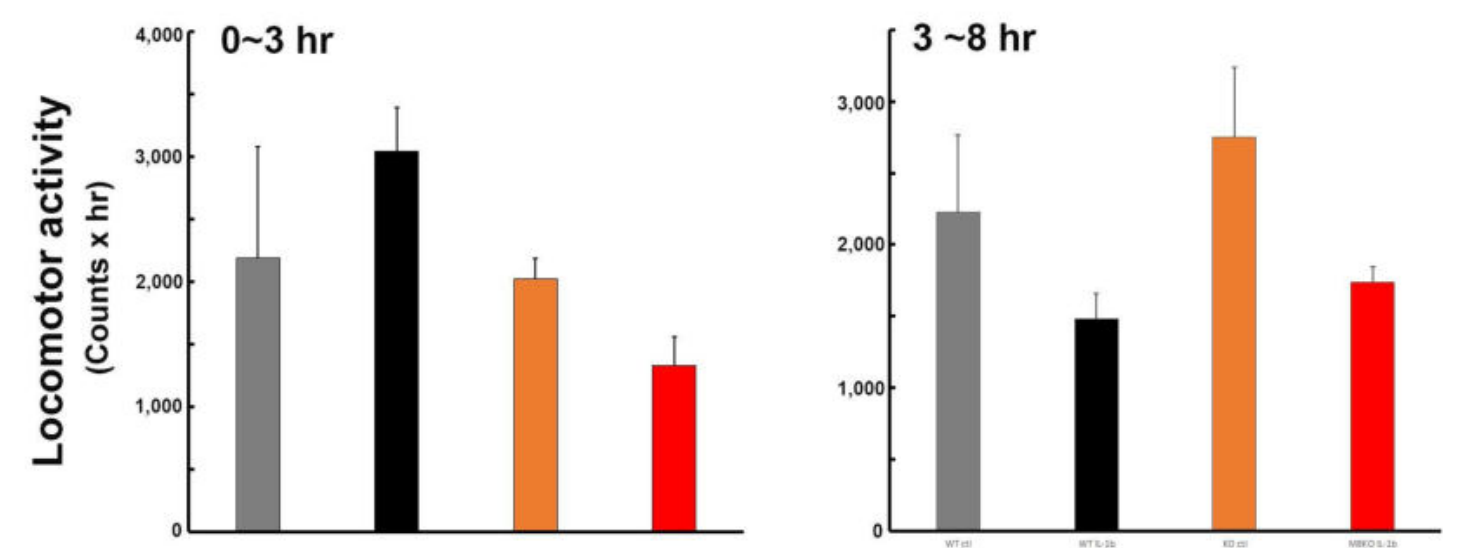


\section{Figure 6}
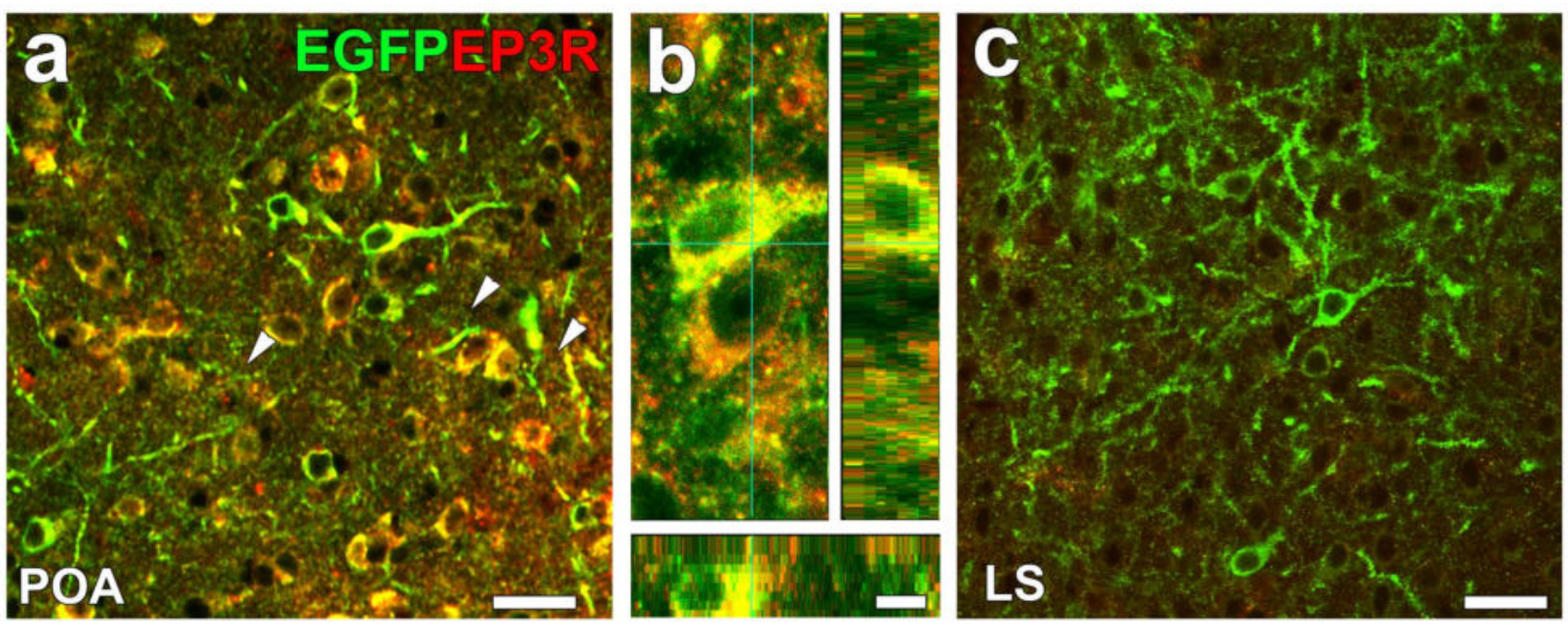

d
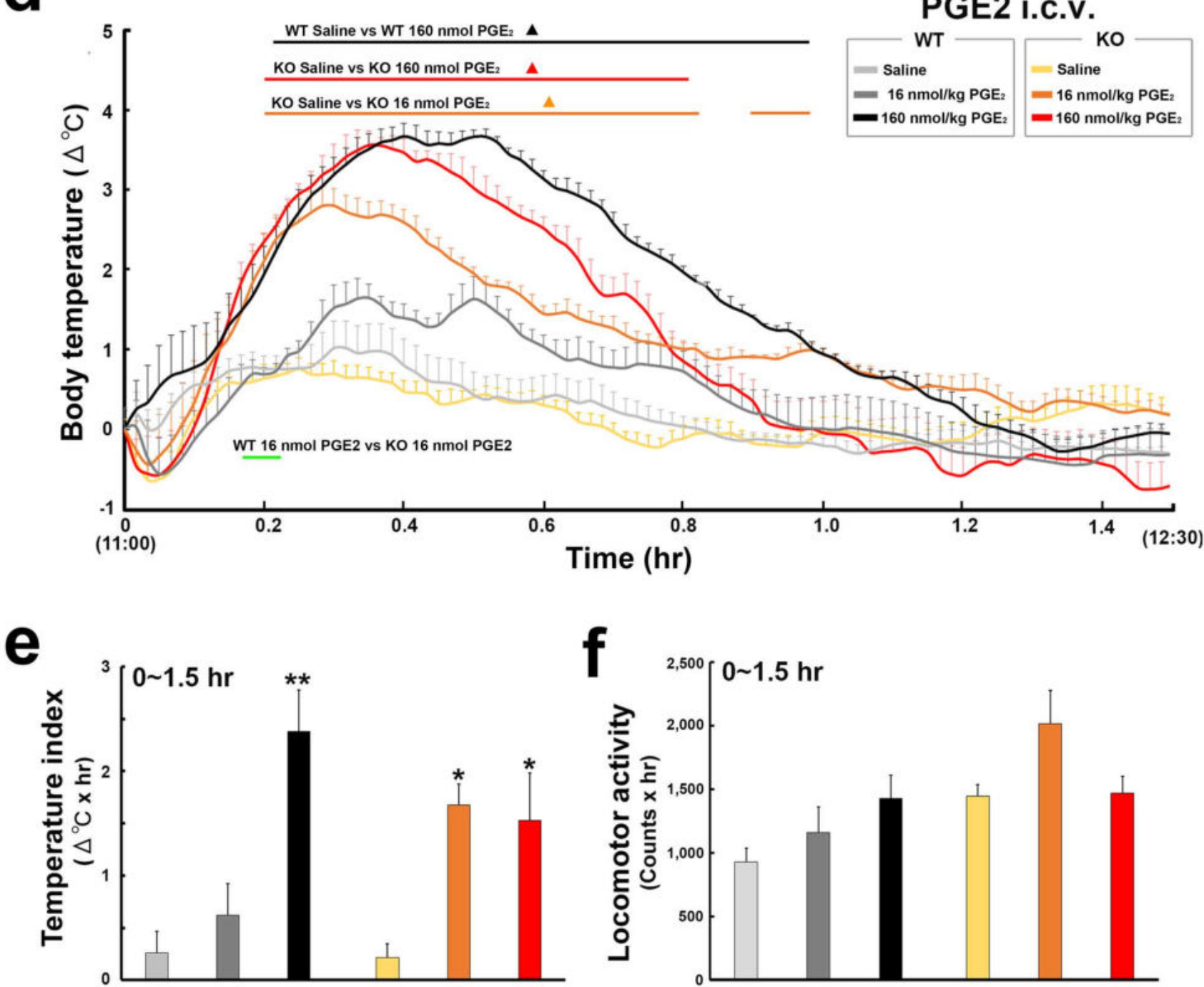


\section{Figure 7}

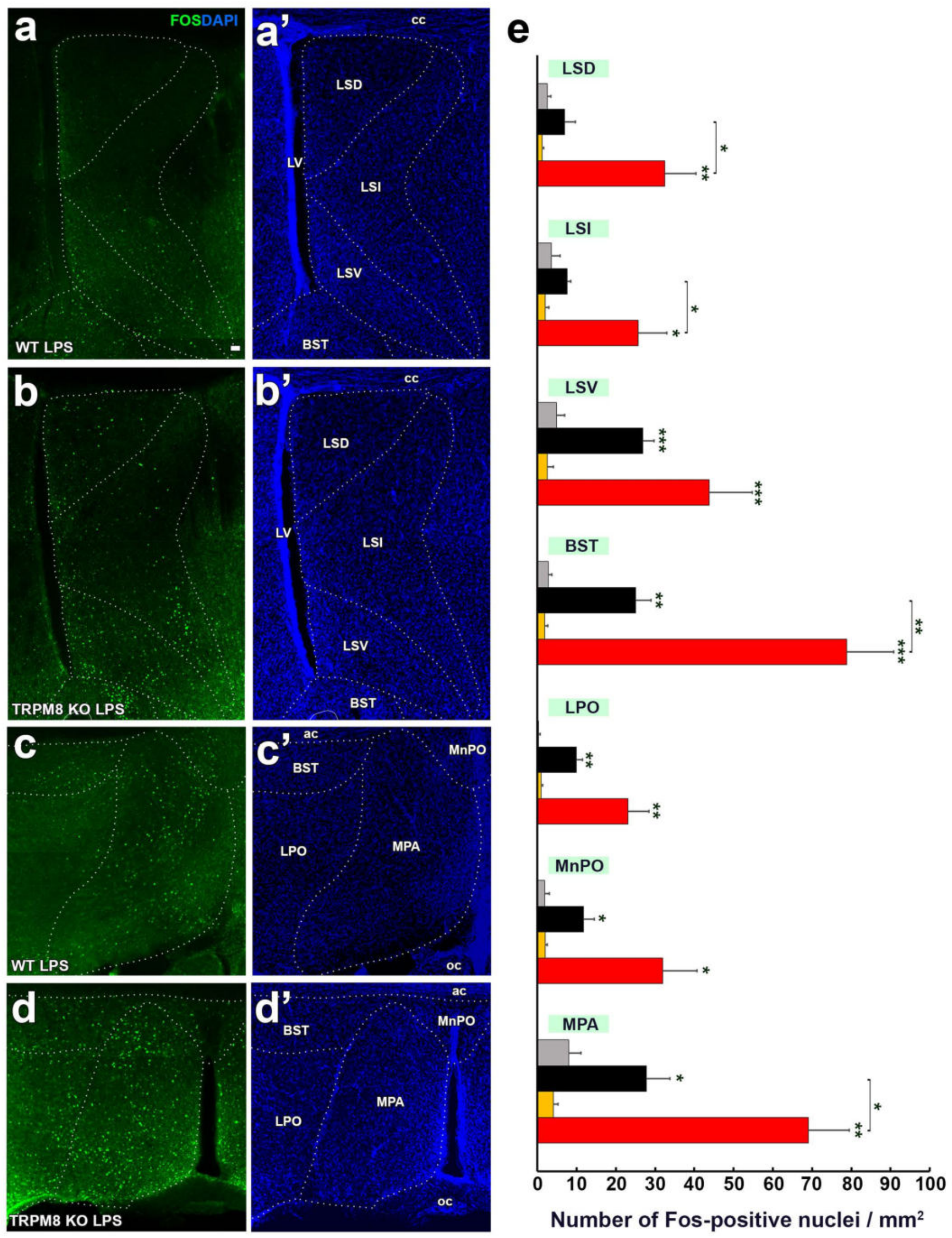


Figure 8

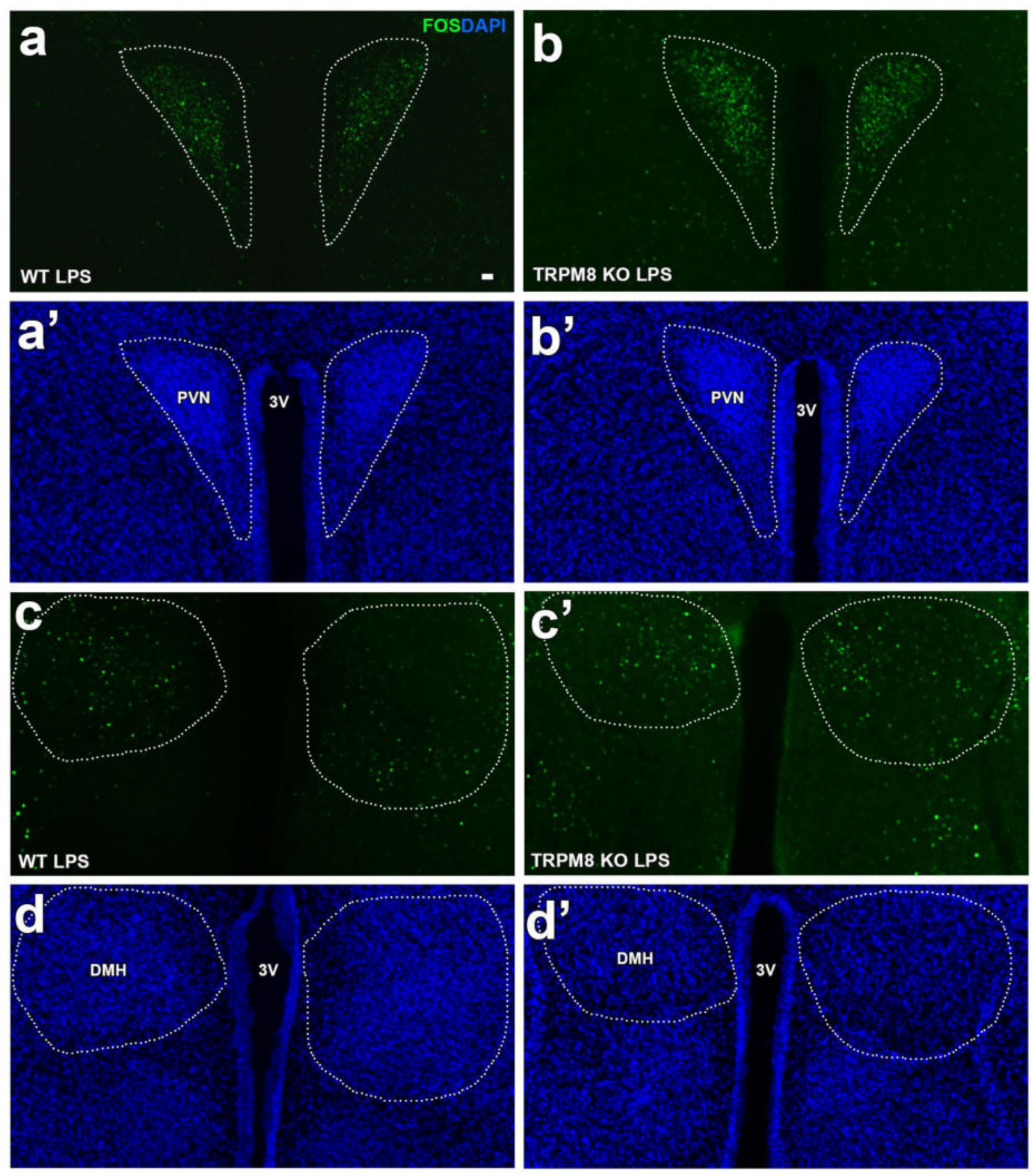

e

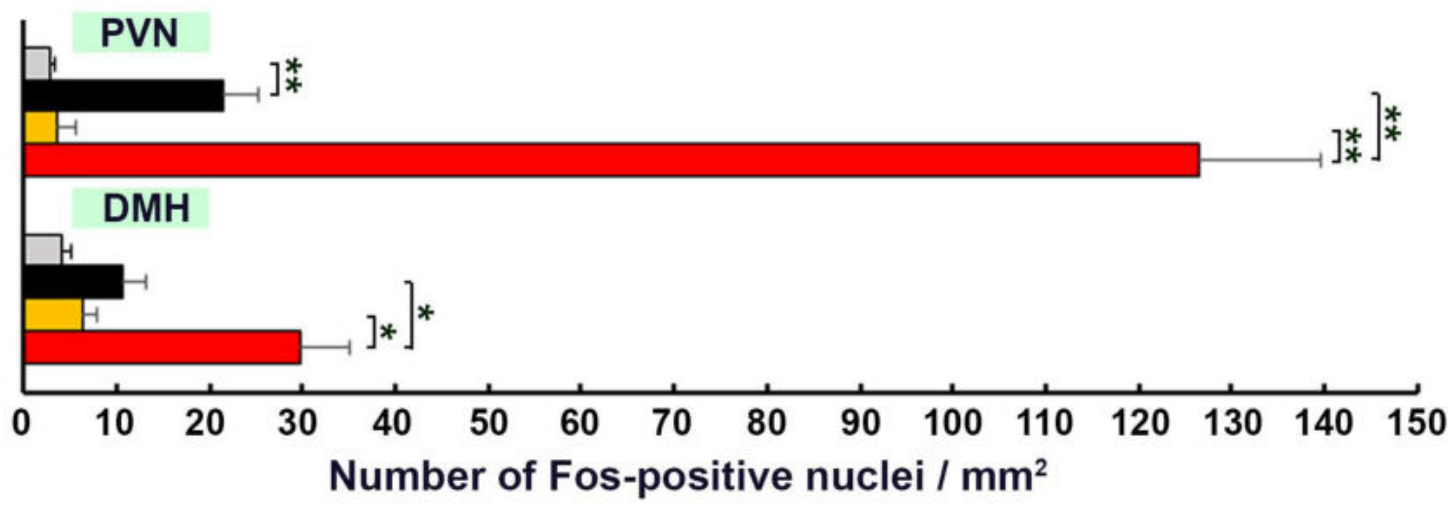




\section{Figures}

a

LPS i.p. $(50 \mu \mathrm{g} / \mathrm{kg})$
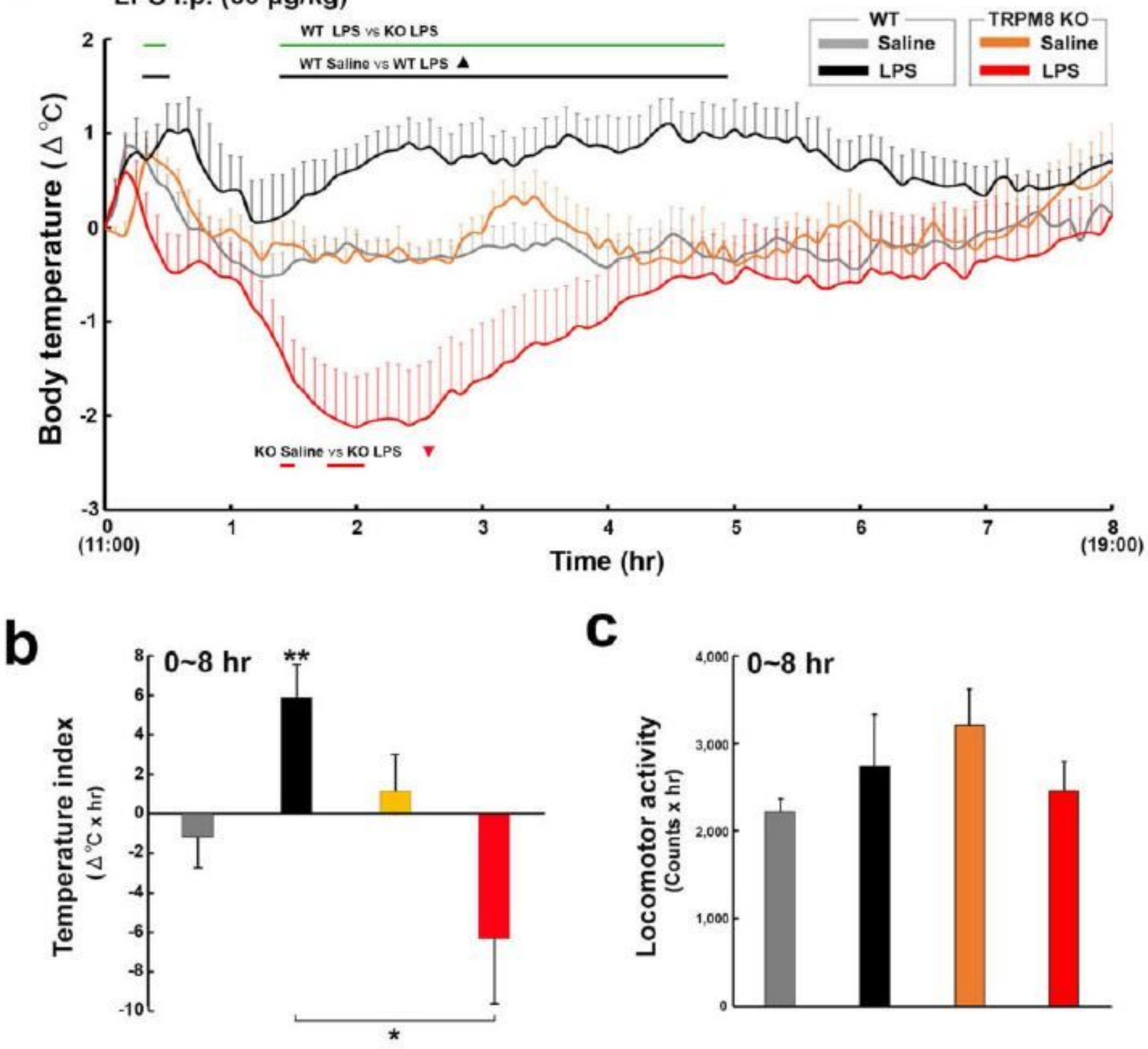

Figure 1

Effects of the intraperitoneal administration of a low dose of the TLR4 agonist, LPS, on the abdominal core temperature and locomotor activity of WT and TRPM8 KO mice. The body temperature and locomotor activity of mice were measured with a G2 E-mitter transponder at an ambient temperature of $25 \pm 0.5^{\circ} \mathrm{C}$ after the intraperitoneal administration of $50 \mu \mathrm{g} / \mathrm{kg}$ LPS. a: The administration of LPS caused hypothermia in TRPM8 KO mice, whereas it induced fever in WT mice. b: The temperature index of LPS- 
treated TRPM8 KO mice was negative, whereas that of LPS-treated WT animals was positive. C:

Cumulative locomotor activity did not significantly differ among groups. Data (WT saline, $n=9$; WT LPS, $n=6$; TRPM8 KO saline, $n=5$; TRPM8 KO LPS, $n=11$ ) are expressed as the mean ( \pm s.e.m.). Lines in a indicate a significant duration $(p<0.05) .{ }^{* *} p<0.01$ among groups by a one-way ANOVA with Tukey's post hoc test.
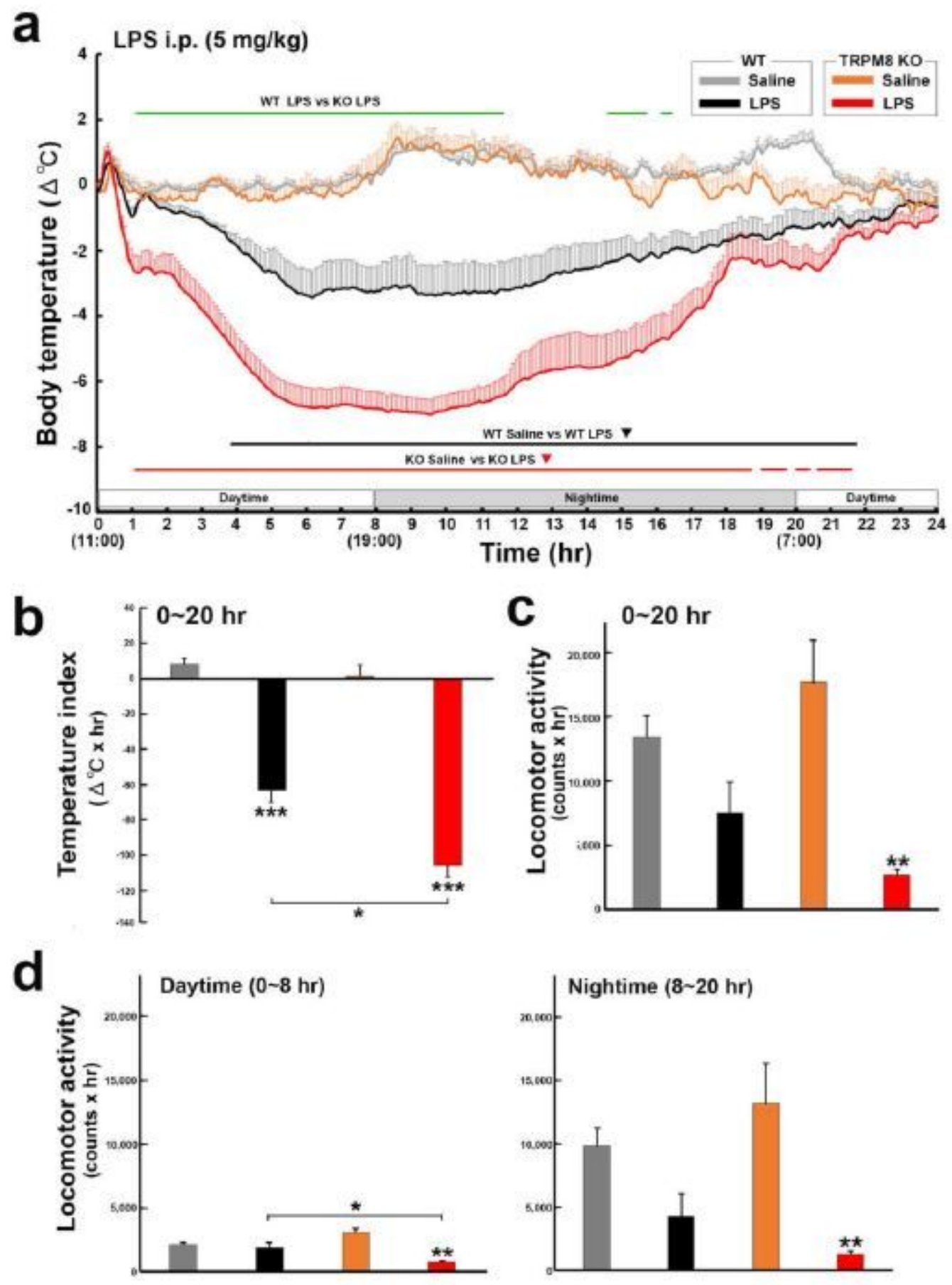

Figure 2

Effects of the intraperitoneal administration of a high dose of the TLR4 agonist, LPS, on the abdominal core temperature and locomotor activity of WT and TRPM8 KO mice. Animals were intraperitoneally 
administered $5 \mathrm{mg} / \mathrm{kg}$ LPS and body temperature and locomotor activity were measured with a G2 Emitter transponder at an ambient temperature of $25 \pm 0.5^{\circ} \mathrm{C}$. a: The body temperature of WT and TRPM8 $\mathrm{KO}$ mice intraperitoneally administered $5 \mathrm{mg} / \mathrm{kg}$ LPS was significantly lower than that of mice administered saline, whereas the core body temperature of TRPM8 KO mice was significantly lower than that of WT animals following the administration of LPS. b: The temperature index was significantly lower in LPS-treated TRPM8 KO mice than in LPS-treated WT mice. c,d: The cumulative locomotor activity of LPS-treated TRPM8 KO mice during all periods examined was markedly lower than that of the saline controls, whereas that of LPS-treated WT animals did not show any significant decrease. Data (WT saline, $n=9$; WT LPS, $n=6$; TRPM8 KO saline, $n=5$; TRPM8 KO LPS, $n=9$ ) are expressed as the mean ( \pm s.e.m.). Lines in a indicate a significant period $(p<0.05)$. ${ }^{*} p<0.05$, $* * p<0.01$, ${ }^{\star \star \star} p<0.001$ among groups by a one-way ANOVA with Tukey's post hoc test. 
a

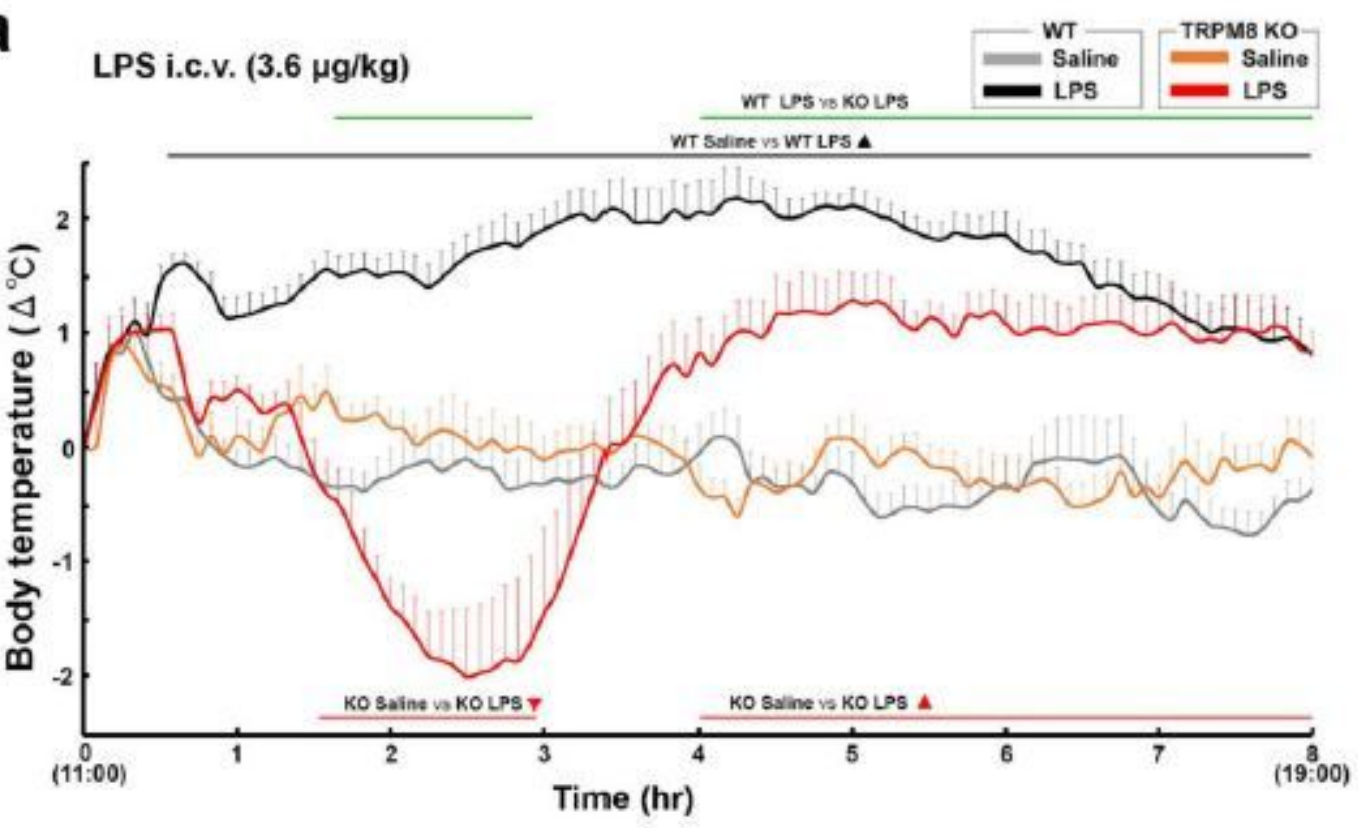

b
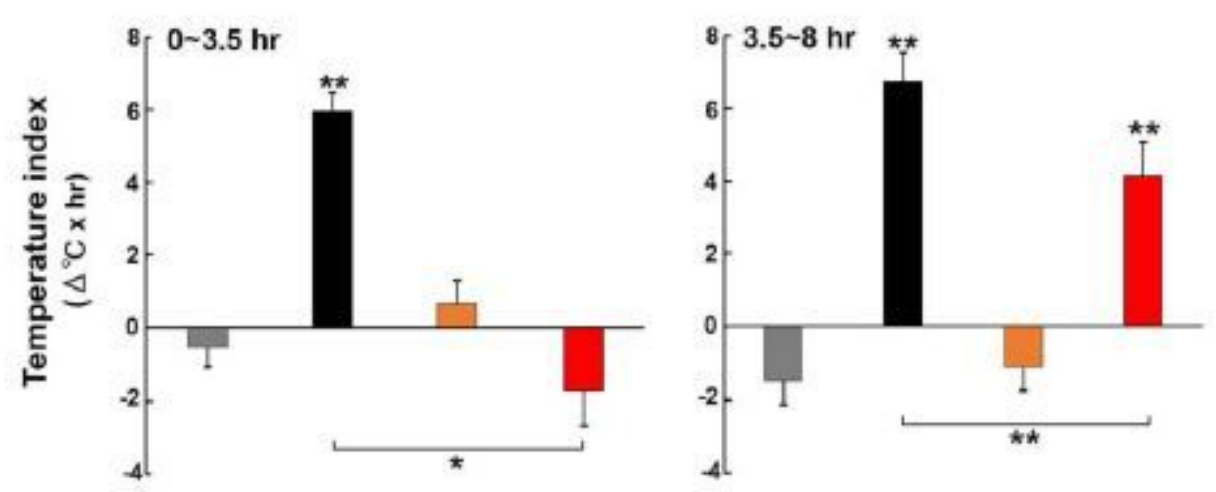

C
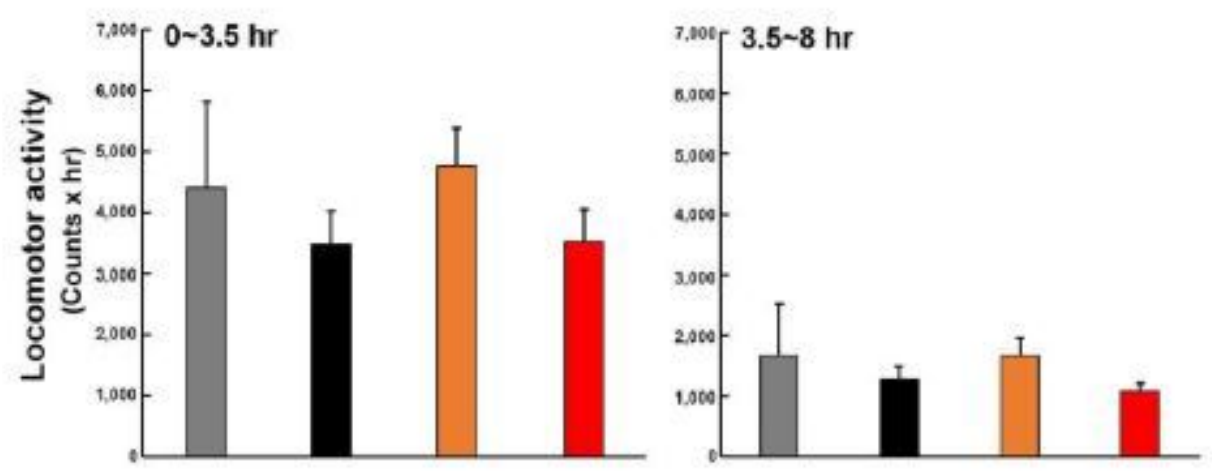

Figure 3

Effects of an i.c.v injection of the TLR4 agonist, LPS, on the abdominal core temperature and locomotor activity of WT and TRPM8 KO mice. Mice received an i.c.v. injection of $3.6 \mu \mathrm{g} / \mathrm{kg}$ LPS and body temperature and locomotor activity were measured with a G2 E-mitter transponder at an ambient temperature of $25 \pm 0.5^{\circ} \mathrm{C}$. a: The i.c.v. injection of LPS induced prominent fever in WT mice throughout the period examined. In contrast, the LPS injection caused hypothermia in TRPM8 KO mice between 1.5 and $3.0 \mathrm{hr}$ after the injection. Body temperature in TRPM8 KO animals then gradually increased from 3.0 
$\mathrm{hr}$ and they developed fever after $4 \mathrm{hr}$. b: The temperature index of LPS-injected TRPM8 KO mice was negative during the early phase ( $0 \sim 3.5 \mathrm{hr})$, whereas that of LPS-injected WT animals was positive. The temperature index of LPS-injected WT and TRPM8 KO mice was positive in the late phase $(3.5 \sim 8.0 \mathrm{hr})$. C: Cumulative locomotor activity was not significantly different among groups. Data (WT saline, $n=6 ; \mathrm{WT}$ LPS, $n=6$; TRPM8 KO saline, $n=7$; TRPM8 KO LPS, $n=6$ ) are expressed as the mean ( \pm s.e.m.). Lines in a indicate a significant period $(p<0.05) .{ }^{*} p<0.05,{ }^{* *} p<0.01$ among groups by a one-way ANOVA with Tukey's post hoc test.

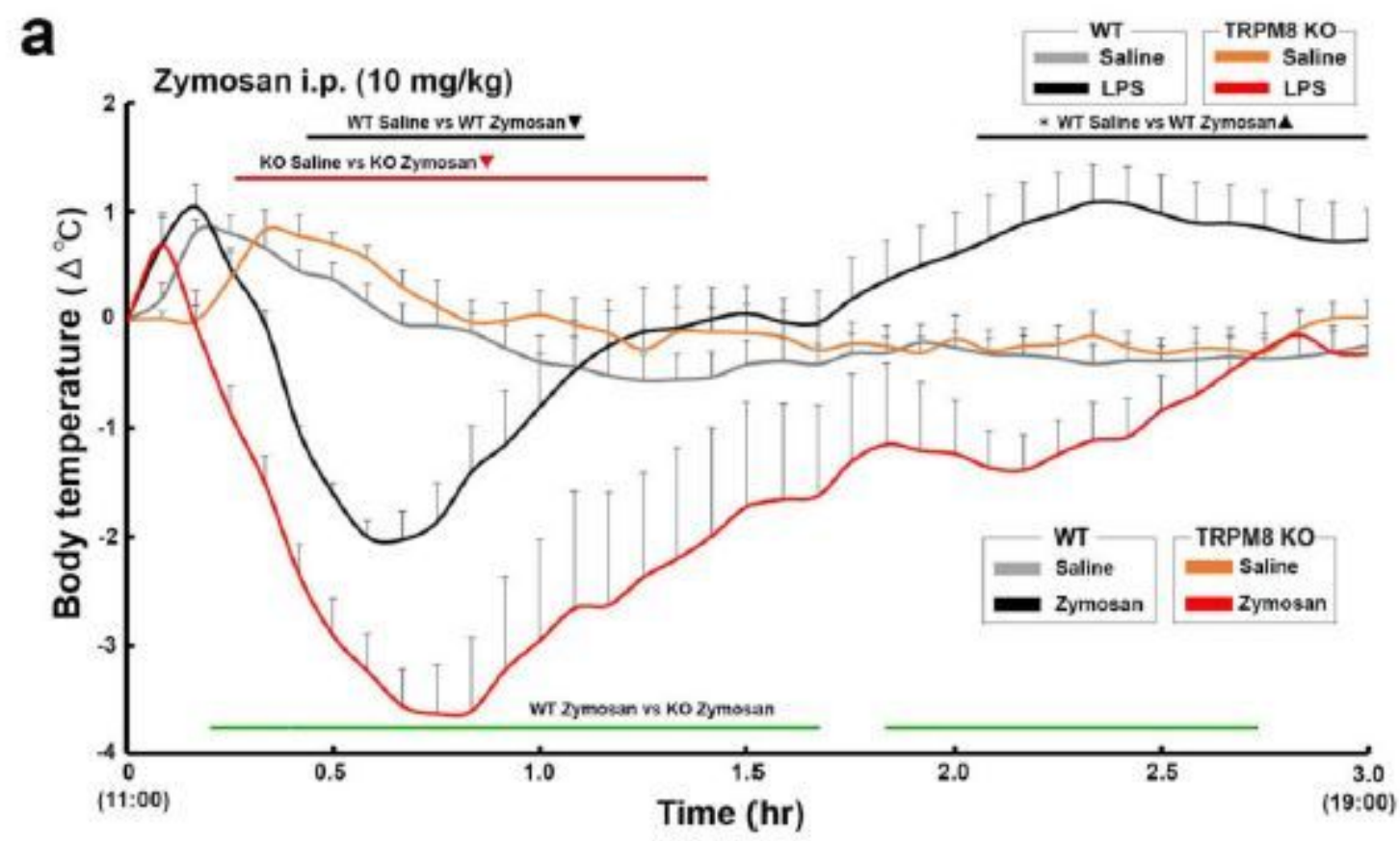

b
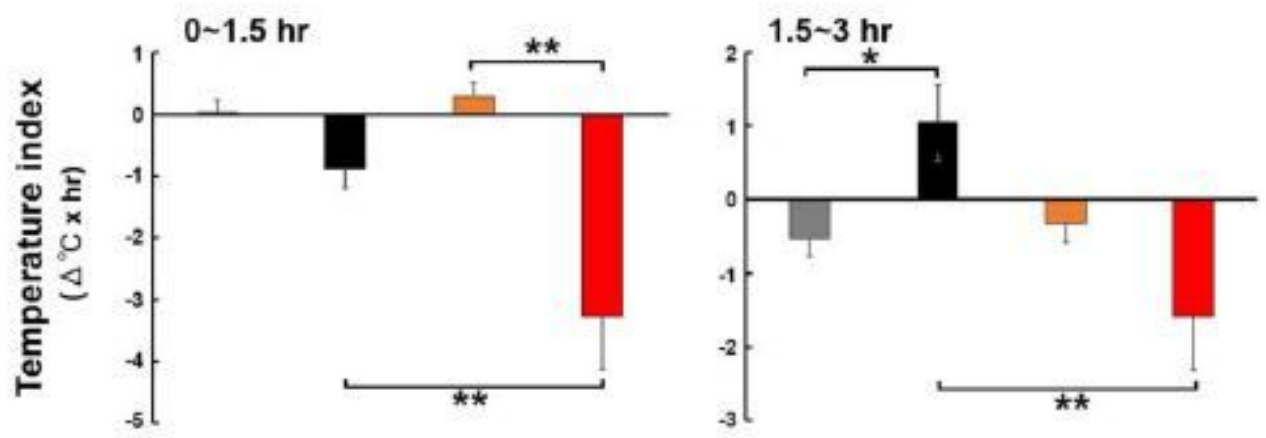

C
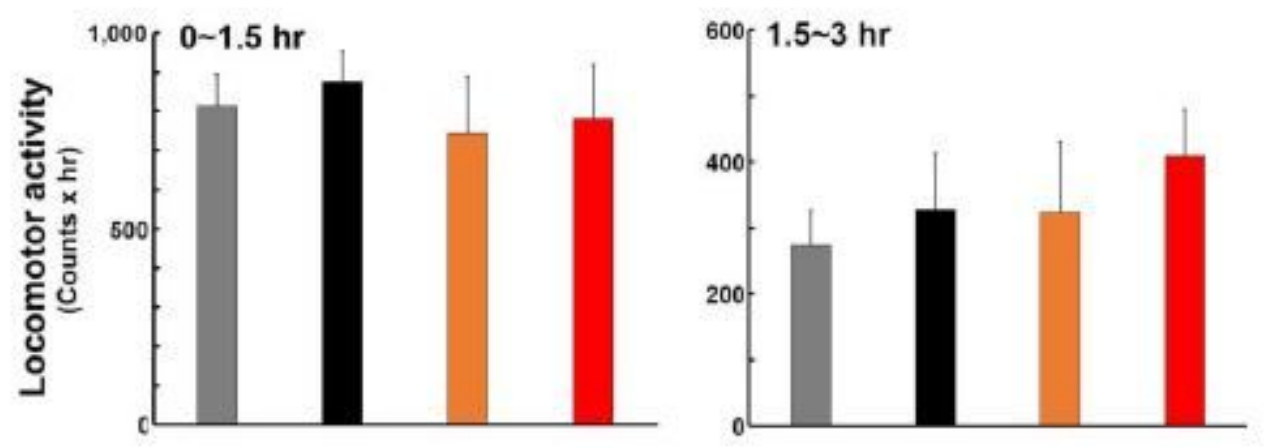


\section{Figure 4}

Effects of the intraperitoneal administration of the TLR2 agonist, zymosan, on the abdominal core temperature and locomotor activity of WT and TRPM8 KO mice. Body temperature and locomotor activity were measured with a G2 E-mitter transponder at an ambient temperature of $25 \pm 0.5^{\circ} \mathrm{C}$ after the intraperitoneal administration of $10 \mathrm{mg} / \mathrm{kg}$ zymosan. a: The intraperitoneal administration of zymosan initially caused hypothermia and then induced fever in WT mice. However,TRPM8 KO mice exhibited hypothermia and did not show fever. b: The temperature index was significantly lower in LPS-injected TRPM8 $\mathrm{KO}$ mice in both the early $(0 \sim 1.5)$ and late $(1.5 \sim 3 \mathrm{hr})$ phases than in WT mice. The temperature index of both LPS-injected WT and TRPM8 KO mice was negative in the early phase, whereas that of LPS-injected WT and TRPM8 KO animals was positive and negative, respectively, in the late phase. c: Cumulative locomotor activity was not significantly different among groups. Data (WT saline, $n=9$; WT zymosan, $n=5$; TRPM8 KO saline, $n=5$; TRPM8 KO zymosan, $n=4$ ) are expressed as the mean ( \pm s.e.m.). Lines in a indicate a significant duration $(p<0.05)$. ${ }^{*} p<0.05,{ }^{*} p<0.01$ among groups by a oneway ANOVA with Tukey's post hoc test. 
a

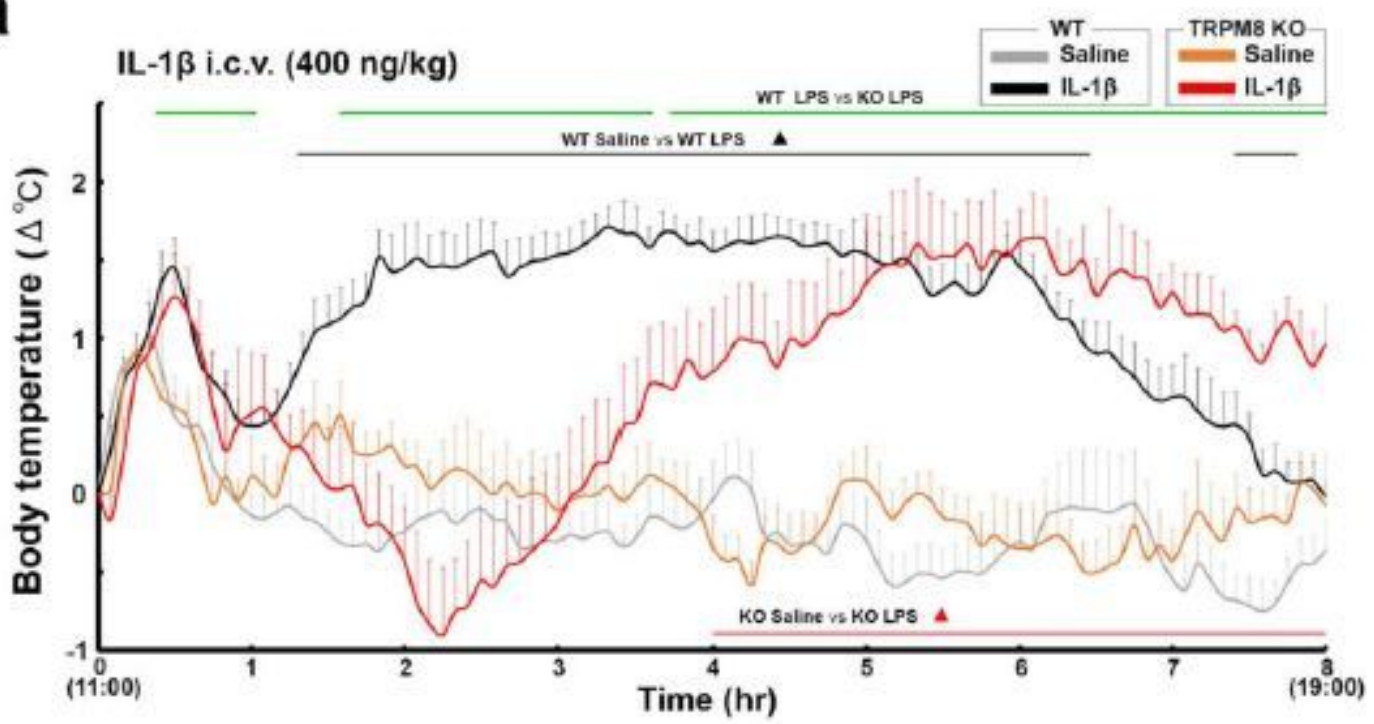

b
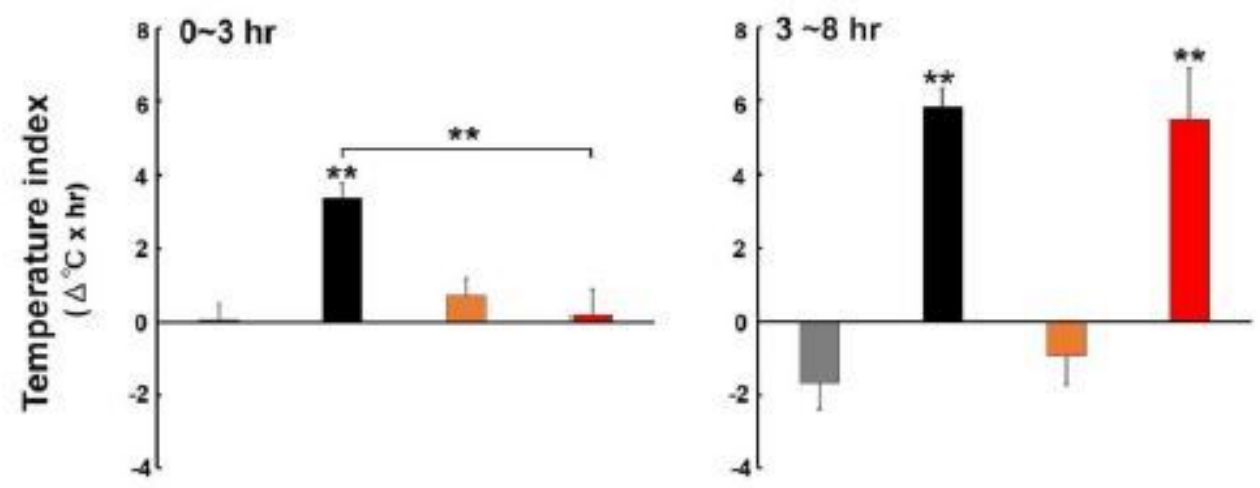

C
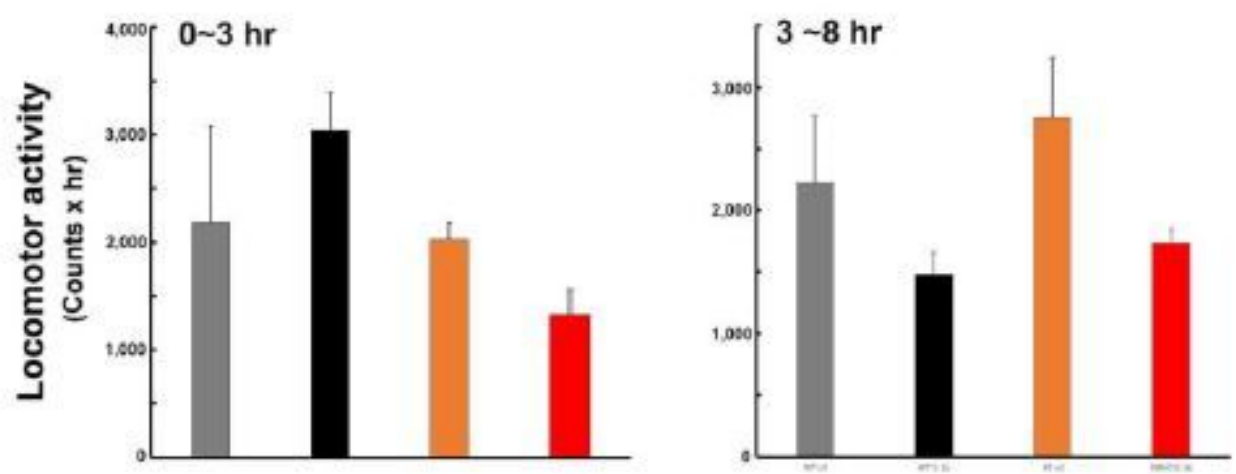

Figure 5

Effects of an i.c.v injection of IL-1 $\beta$ on the abdominal core temperature and locomotor activity of WT and TRPM8 KO mice. Mice received an i.c.v. injection of $400 \mathrm{ng} / \mathrm{kg} \mathrm{IL-1 \beta}$ and body temperature and locomotor activity were measured with a G2 E-mitter transponder at an ambient temperature of $25 \pm 0.5^{\circ} \mathrm{C}$. a: The i.c.v. injection of IL-1 $\beta$ induced fever in WT mice, but not in their saline controls, whereas TRPM8 KO mice did not show fever in the early phase (0 3 hr), but developed fever in the late phase (3 8 hr). b: The temperature index was significantly different between WT and TRPM8 KO mice in the early phase following the IL-1 $\beta$ injection, but not in the late phase. c: Cumulative locomotor activity was not 
significantly different among groups. Data (WT saline, $n=6$; WT IL-1 $\beta, n=6$; TRPM8 KO saline, $n=7$; TRPM8 KO Pam3CSK4, $n=4$ ) are expressed as the mean ( \pm s.e.m.). Lines in a indicate a significant time $(p<0.05) .{ }^{*} p<0.01$ among groups by a one-way ANOVA with Tukey's post hoc test.
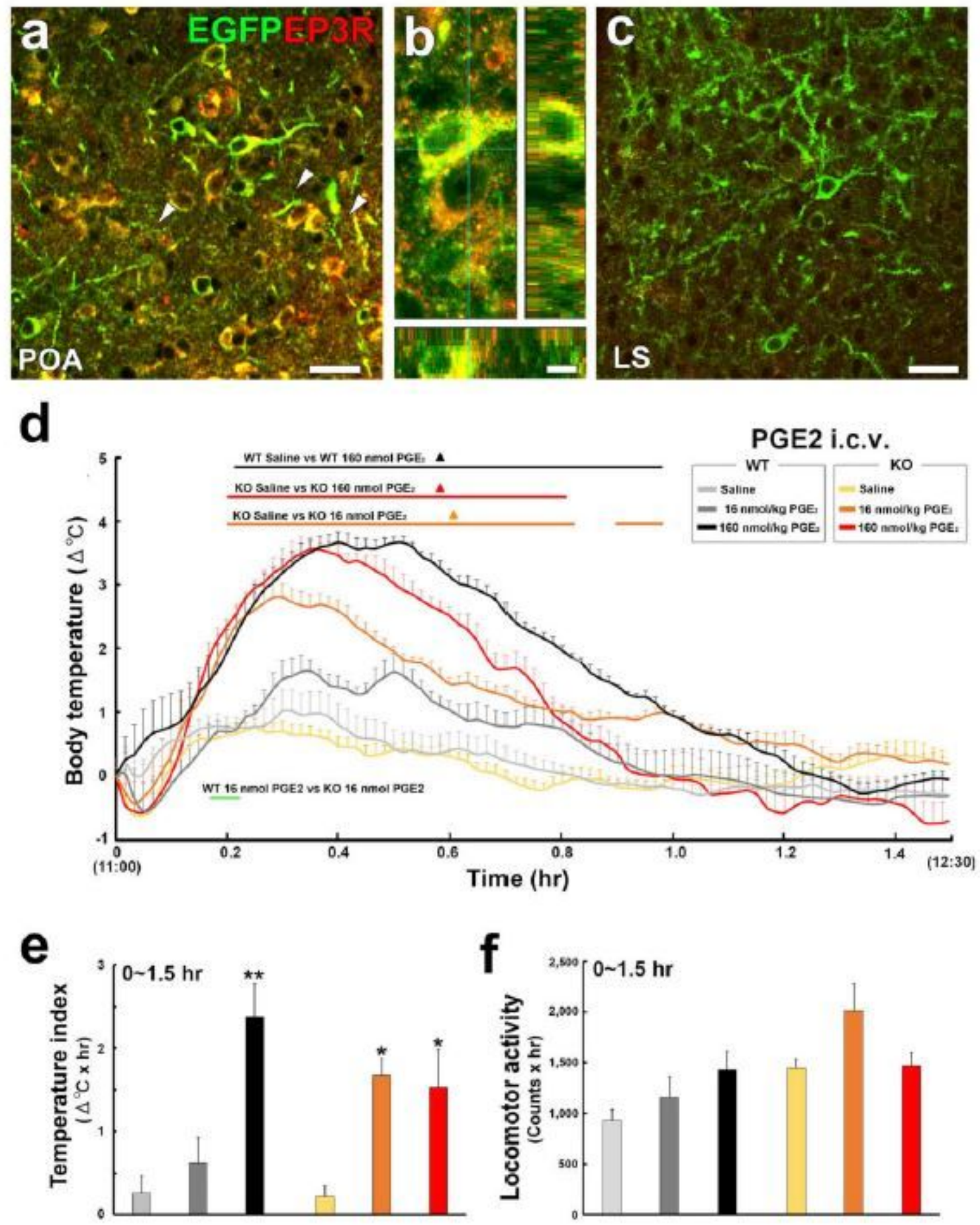

Figure 6

Colocalization of TRPM8 and EP3R in the POA and LS and effects of an i.c.v injection of PGE2 on the abdominal core temperature and locomotor activity of WT and TRPM8 KO mice. Cryosections were 
immunostained with GFP and EP3R in TRPM8 KO mice with EGFP knocked in at the start codon of TRPM8, resulting in the expression of EGFP instead of TRPM8. a-c: EGFP-expressing TRPM8 neurons (arrowheads) often expressed EP3R in the POA (a). A 3D analysis showed the colocalization of EGFP and EP3R (b). The majority of EGFP- expressing TRPM8 neurons very weakly expressed EP3R in the LS. Scale bars $=50$ (a), 10 (b) $\mu \mathrm{m}$. d: Mice received an i.c.v. injection of 16 or $160 \mathrm{nmol} / \mathrm{kg}$ PGE2 and body temperature and locomotor activity were measured with a G2 E-mitter transponder at an ambient temperature of $25 \pm 0.5^{\circ} \mathrm{C}$. The i.c.v. injection of PGE2 induced prominent fever in both WT and TRPM8 $\mathrm{KO}$ mice. e: The temperature index was significantly increased in WT and TRPM8 KO mice by the i.c.V. injection of PGE2. $\mathrm{f}$ : Cumulative locomotor activity was not significantly different among groups. Data (WT: saline, $\mathrm{n}=6 ; 16 \mathrm{nmol} / \mathrm{kg}$ PGE2, $\mathrm{n}=4 ; 160 \mathrm{nmol} / \mathrm{kg}$ PGE2, $\mathrm{n}=4$; TRPM8 KO: saline, $\mathrm{n}=7 ; 16$ $\mathrm{nmol} / \mathrm{kg}$ PGE2, $\mathrm{n}=5 ; 160 \mathrm{nmol} / \mathrm{kg}$ PGE2) are expressed as the mean ( \pm s.e.m.). Lines in d indicate a significant period $(p<0.05)$. ${ }^{*}<0.05,{ }^{*} p<0.01$ among groups by a one-way ANOVA with Tukey's post hoc test. 

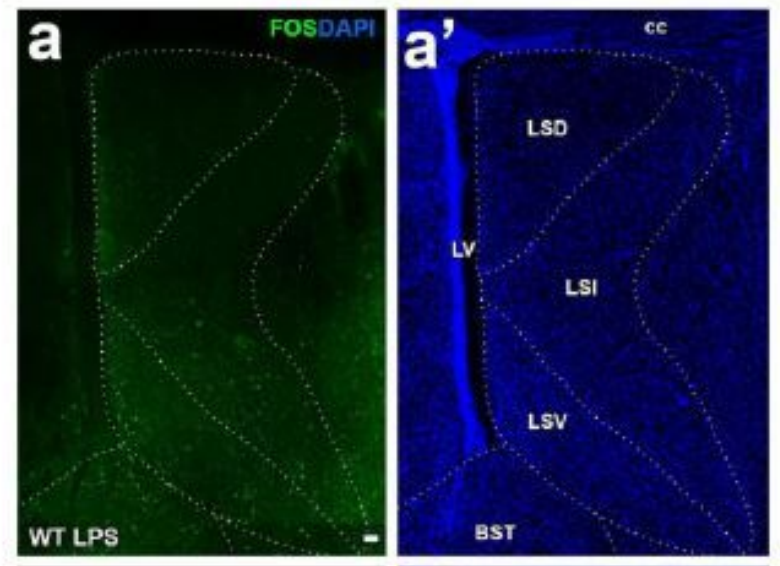

e
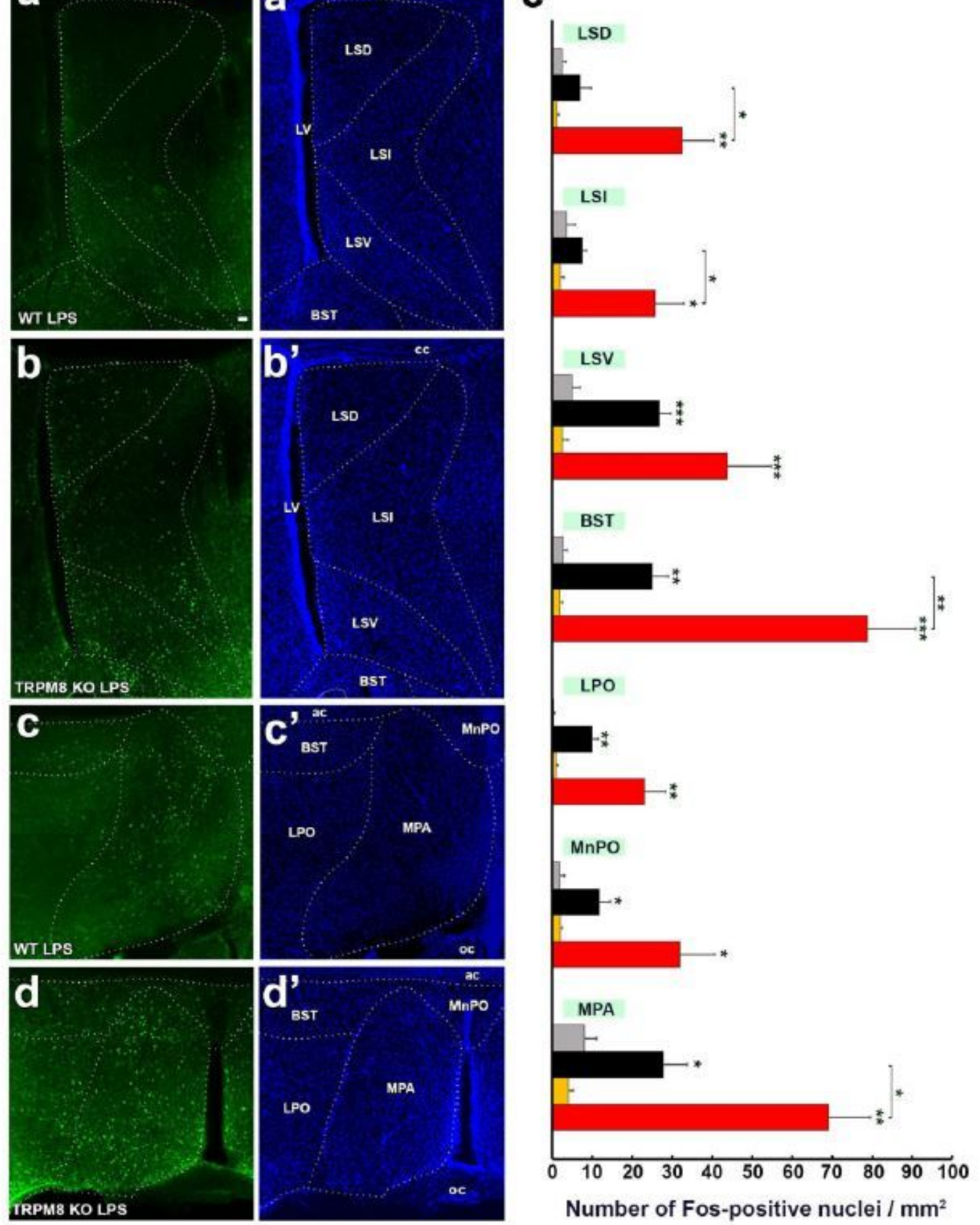

\section{Figure 7}

Effects of the intraperitoneal administration of a low dose of the TLR4 agonist, LPS, on Fos expression in the POA and LS of WT and TRPM8 KO mice. Animals were intraperitoneally administered $50 \mu \mathrm{g} / \mathrm{kg}$ LPS and were then sacrificed for Fos immunohistochemistry 2 hours after the injection. a-d, a-d': Fluorescent images revealed many Fos+ nuclei in the POA and LS of both WT and TRPM8 KO mice. e: The number of Fos+ nuclei in the LSD, LSI, BST, and MPA was significantly higher in LPS-treated TRPM8 KO mice than in 
WT mice. Data $(n=4)$ were expressed as the mean \pm s.e.m. *: $P<0.05, * \star$ : $P<0.01$, ***: $P<0.01$ vs control WT mice. Statistical analyses were performed using the Student's t-test. Fig.
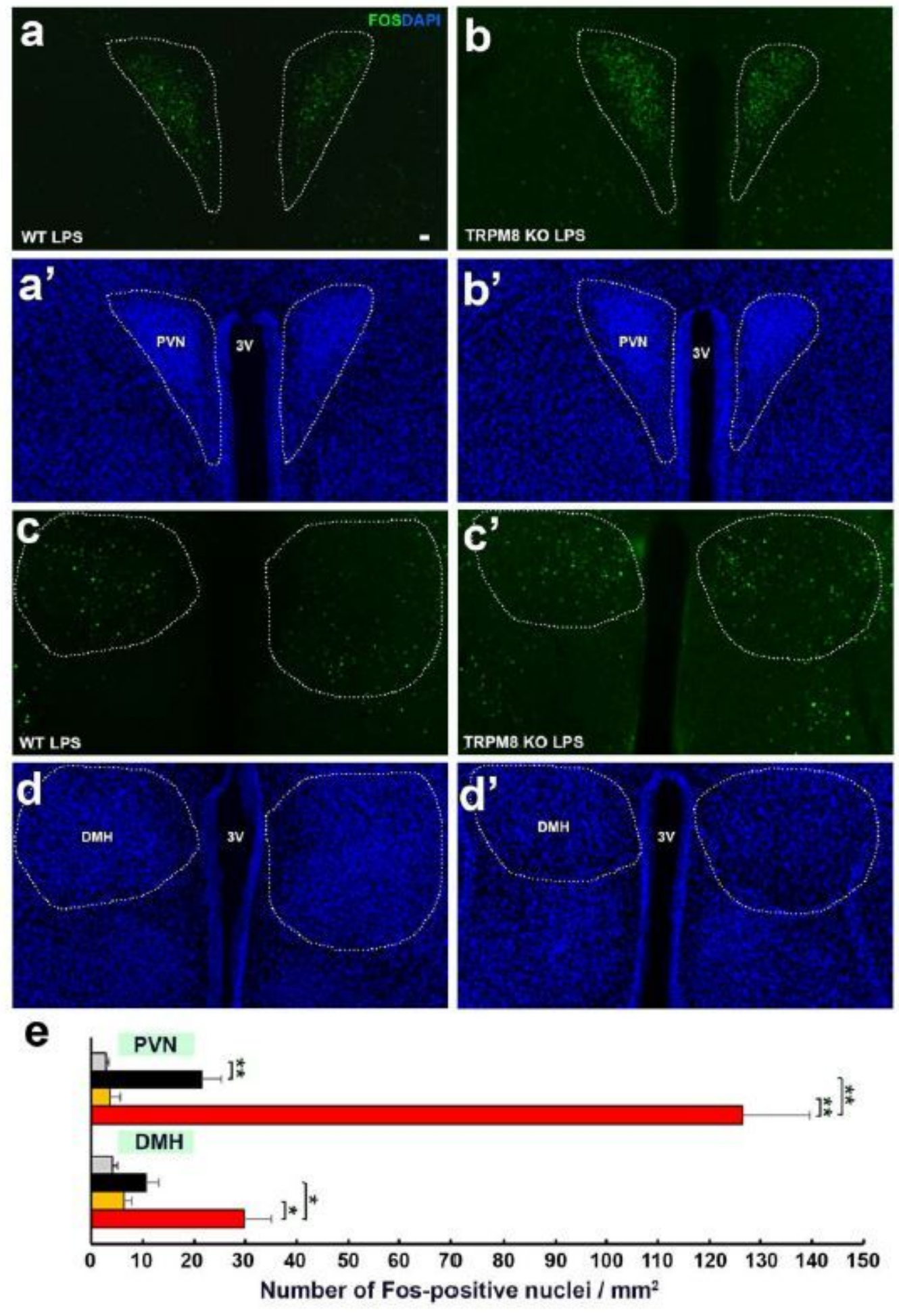

\section{Figure 8}

Effects of the intraperitoneal administration of a low dose of the TLR4 agonist, LPS, on Fos expression in the PVN and DMH of WT and TRPM8 KO mouse. Animals were intraperitoneally administered $50 \mu \mathrm{g} / \mathrm{kg}$ LPS and were then sacrificed for Fos immunohistochemistry 2 hours after the injection. a-d, a-d': 
Fluorescent images revealed many Fos+ nuclei in the PVN and DMH of both WT and TRPM8 KO mice. e: The number of Fos+ nuclei in the PVN and DMH was significantly higher in LPS-treated TRPM8 KO mice than in WT mice. Data $(n=4)$ were expressed as the mean \pm s.e.m. $*: P<0.05, * *: P<0.01, * \star *: P<0.01$ vs control WT mice. Statistical analyses were performed using the Student's t-test.

\section{Supplementary Files}

This is a list of supplementary files associated with this preprint. Click to download.

- SupplementaryFiguresS19Shirakietal..pdf 